\title{
Dysfunction of Microglial STAT3 Alleviates Depressive Behavior via Neuron-Microglia Interactions
}

\begin{abstract}
Sun-Ho Kwon 1,2,3,9, Jeong-Kyu Han 2,4,5,9, Moonseok Choi', Yong-Jin Kwon', Sung Joon Kim ${ }^{4}$, Eun Hee Yi ${ }^{6}$, Jae-Cheon Shin ${ }^{7}$, Ik-Hyun Cho ${ }^{8}$, Byung-Hak Kim ${ }^{1,3}$, Sang Jeong Kim ${ }^{*, 2,3,4,5}$ and Sang-Kyu Ye ${ }^{*, 1,2,3,6}$

'Department of Pharmacology, Seoul National University College of Medicine, Seoul, Republic of Korea; ${ }^{2}$ Neuro-Immune Information Storage Network Research Center, Seoul National University College of Medicine, Seoul, Republic of Korea; ${ }^{3}$ Biomedical Science Project (BK2 I [PLUS]), Seoul National University College of Medicine, Seoul, Republic of Korea; ${ }^{4}$ Department of Physiology, Seoul National University College of Medicine, Seoul, Republic of Korea; ${ }^{5}$ Department of Brain and Cognitive Sciences, Seoul National University Graduate School, Seoul, Republic of Korea; ${ }^{6}$ Ischemic/Hypoxic Disease Institute, Seoul National University College of Medicine, Seoul, Republic of Korea; ${ }^{7}$ Pohang Center for Evaluation of Biomaterials, Pohang, Republic of Korea; ${ }^{8}$ Department of Convergence Medical Science, College of Oriental Medicine, Kyung Hee University, Seoul, Republic of Korea
\end{abstract}

Neuron-microglia interactions have a crucial role in maintaining the neuroimmune system. The balance of neuroimmune system has emerged as an important process in the pathophysiology of depression. However, how neuron-microglia interactions contribute to major depressive disorders has been poorly understood. Herein, we demonstrated that microglia-derived synaptic changes induced antidepressive-like behavior by using microglia-specific signal transducer and activator of transcription 3 (STAT3) knockout (KO) $\left(\right.$ STAT3 $^{\mathrm{f} / \mathrm{fl}} ; \mathrm{LysM}$-Cre ${ }^{+/-}$) mice. We found that microglia-specific STAT3 KO mice showed antidepressive-like behavior in the forced swim, tail suspension, sucrose preference, and open-field tests. Surprisingly, the secretion of macrophage colony-stimulating factor (M-CSF) was increased from neuronal cells in the brains of STAT3 ${ }^{\mathrm{fl} / \mathrm{fl}}$;LysM-Cre ${ }^{+/-}$mice. Moreover, the phosphorylation of antidepressant-targeting mediators and brain-derived neurotrophic factor expression were increased in the brains of STAT3 ${ }^{\mathrm{fl} / \mathrm{f}} ; \mathrm{LysM}_{\mathrm{M}} \mathrm{Cre}{ }^{+/-}$mice as well as in neuronal cells in response to M-CSF stimulation. Importantly, the miniature excitatory postsynaptic current frequency in the medial prefrontal cortex was increased in STAT3 ${ }^{f / f f l} ; \mathrm{LySM}-\mathrm{Cre}^{+/-}$mice and in the M-CSF treatment group. Collectively, microglial STAT3 regulates depression-related behaviors via neuronal M-CSF-mediated synaptic activity, suggesting that inhibition of microglial STAT3 might be a new therapeutic strategy for depression.

Neuropsychopharmacology (2017) 42, 2072-2086; doi:I0.1038/npp.2017.93; published online 7 June 2017

\section{INTRODUCTION}

Neuron-microglia interactions have a crucial role in maintaining the neuroimmune system (Rogers et al, 2011; Wake et al, 2013; Zhan et al, 2014). Recent evidence has focused on the imbalance of the neuroimmune system in association with psychiatric disorders, such as major depression (Couch et al, 2013). Presumably, microglial dysfunction causes disturbances in synaptic regulation, resulting in major depression. However, the cellular and molecular mechanisms of major depression underpinning the bidirectional interplay between neurons and microglia remain unclear.

* Correspondence: Dr Sang-Kyu Ye, Department of Pharmacology, Seoul National University College of Medicine, Seoul, South Korea. Tel: +82 2740 828I, Fax: +82 2745 7996, E-mail: sangkyu@snu.ac.kror Dr Sang Jeong Kim, Department of Physiology, Seoul National University College of Medicine, Seoul, South Korea. Tel: +82 2740 8229, Fax: +82 2

763 9667, E-mail: sangjkim@snu.ac.kr

${ }^{9}$ These authors contributed equally to this work.

Received 2 December 2016; revised 27 April 2017; accepted I May 2017; accepted article preview online 8 May 2017
For decades, many studies focused on novel therapeutic approaches for major depression (Domino et al, 2008; Goodyer et al, 2007). The intracellular signaling pathways of extracellular signal-regulated kinase (ERK) $1 / 2$, Akt and glycogen synthase kinase-3 $\beta$ (GSK3 $\beta$ ) have been identified as the potent targets for antidepressants (Duman et al, 2016). According to postmortem studies, ERK1/2 signaling, which is downregulated in the brains of patients with major depression (Dwivedi et al, 2005; Dwivedi et al, 2001), has been implicated in antidepressant treatment (Duman et al, 2012b; Einat et al, 2003; Tardito et al, 2006). Although the blockade of the ERK signaling pathway leads to depressionrelated behaviors, antidepressant treatments increase ERK phosphorylation (Gourley et al, 2007; Hisaoka et al, 2007). In addition, GSK $3 \beta$ is regarded as a key factor involved in psychiatric diseases (Beurel et al, 2015; Chuang et al, 2011; Jope and Roh, 2006). Recent studies showed increased GSK3 $\beta$ activity in the cortical regions of postmortem brains of suicide victims who had suffered from depression (Karege et al, 2007). However, the inactivation of GSK3 $\beta$ using lithium or valproate may alleviate unipolar depression (Chen et al, 2000; Cipriani et al, 2006; Davis et al, 1996). GSK3 $\beta$ is 
also negatively regulated by phosphatidylinositol 3-kinasemediated Akt activation (Fang et al, 2000).

Despite having a sufficient knowledge of ERK1/2 and Akt/ GSK3 $\beta$ signaling pathways, the etiological factors leading to major depression remain unknown. Recent studies showed that neuroinflammation caused by stress-induced activation of microglia leads to depressive-like behaviors (Brites and Fernandes, 2015; Steiner et al, 2011; Streit et al, 2004). In addition to microglial activation, microglial senescence and decline can negatively affect neurogenesis, causing major depression (Caldeira et al, 2014; Kreisel et al, 2014). These findings suggest the importance of microglial activation status in depression.

Microglia provide pro- and anti-inflammatory cytokines as mediators for the neuroimmune system. Signal transducer and activator of transcription 3 (STAT3) is one of the transcription factors for cytokine production (El Kasmi et al, 2006), such as soluble intracellular cell adhesion molecule-1 (sICAM-1) (Park et al, 2013), interleukin (IL)-6 (Mori et al, 2011), IL-10 (Riley et al, 1999), tumor necrosis factor- $\alpha$ (TNF- $\alpha$ ) (Chabot et al, 1997; Riazi et al, 2008) and IL-1 $\beta$ (Clausen et al, 2008). These cytokines have been identified as mediators for the neuroimmune system of depression (Hodes et al, 2015). For example, the IL-6/STAT3 signaling pathway was shown to be involved in depressive-like behavior (Kong et al, 2015). In addition, pathological levels of these cytokines contribute to behavioral deficits such as depressive-like behavior (Audet and Anisman, 2013; Felger and Lotrich, 2013; Khairova et al, 2009; Schiepers et al, 2005), requiring a more sophisticated manipulation of cytokine levels.

In this study, we hypothesized that STAT3 signaling in microglia affects neuron-microglia interactions via secreted cytokines, resulting in synaptic and behavioral changes. To investigate the key factors regulated by microglial STAT3 in neuron-microglia interactions, we used microglia-targeted STAT3-deficient mice and analyzed the molecular mechanisms and their behavioral phenotypes. As a result, we revealed that STAT3 dysfunction in microglia led to antidepressive-like behavior via crosstalk between neurons and microglia, suggesting a novel therapeutic avenue for major depression.

\section{MATERIALS AND METHODS}

\section{Experimental Animals and Genotyping}

Mice homozygous for the loxP-flanked (floxed) Stat3 gene $\left(\mathrm{STAT} 3^{\mathrm{fl} / \mathrm{fl}}\right.$ ) were kindly gifted from Dr S Akira. Mice carrying a Cre transgene under the control of the distal LysM promoter (LysM-Cre ${ }^{+/+}$) were purchased from the Jackson Laboratory (Bar Harbor, ME). Mice with a STAT3 deletion in myeloid cells were generated by crossing mice with the floxed STAT3 allele with mice expressing Cre under the control of the LysM promoter. Genomic DNA was isolated from tail tips using a NucleoSpin genomic DNA purification kit (Macherey-Nagel GmbH, Duren, North Rhine-Westphalia, Germany). The PCR reaction was performed using AccuPower PCR premix (Bioneer, Daejeon, Korea) with the primers, which are specific for exons 22 and 23 of STAT3 and Cre transgene, according to the manufacturer's instructions. All experiments were performed with male mice aged 8-10 weeks. Experimental animals were maintained under specific pathogen-free conditions and $22 \pm 1^{\circ} \mathrm{C}$ with a reversed $12 \mathrm{~h}$ light-dark cycle (lights on at $0700 \mathrm{~h}$ ). All experimental procedures were reviewed and approved by the Institutional Animal Care and Use Committee at the College of Medicine, Seoul National University.

\section{Primary Microglia Cell Culture}

Primary microglia cells were isolated from primary mixed glial cells of 2-day-old mice. To obtain mixed glial cells, cerebral cortices were dissected, carefully stripped of their meninges, and dissociated into a single-cell suspension by trituration. Cells were cultured on poly-L-lysine (SigmaAldrich, St Louis, MO)-coated $100 \mathrm{~mm}^{2}$ culture dish in Dulbecco's modified Eagle's medium (DMEM, Hyclone, Logan, UT) containing 10\% fetal bovine serum (FBS) and 1\% penicillin-streptomycin solution (Gibco, Grand Island, NY), and incubated at $37^{\circ} \mathrm{C}$ in $5 \% \mathrm{CO}_{2}$. On the third day of culture, cells were vigorously washed with pipetting and the media was replaced to remove debris. After 6 days in vitro, cells were transferred to a T-75 flask and incubated for 13 weeks. Then, the conditioned media were replaced with fresh media to achieve complete confluence. To isolate microglia, the T-75 flask was rotated $\left(200 \mathrm{rpm}, 37^{\circ} \mathrm{C}, 5 \mathrm{~h}\right)$ using a temperature-controlled, non-humidified shaker, and then supernatant media containing microglia was centrifuged $(215 \mathrm{~g}, 5 \mathrm{~min})$. The microglial pellet was suspended and seeded onto poly-L-lysine-coated $60 \mathrm{~mm}^{2}$ cover glassbottom dish (SPL Life Sciences, Pocheon, Korea), and incubated at $37^{\circ} \mathrm{C}$ in $5 \% \mathrm{CO}_{2}$.

\section{Cell Culture and Co-Culture Experiments}

Mouse microglia cell line BV2 and mouse hippocampal neuronal cell line HT22 (ATCC, Manassas, VA) were cultured in DMEM containing 10\% FBS and $1 \%$ penicillinstreptomycin solution, and incubated at $37^{\circ} \mathrm{C}$ in $5 \% \mathrm{CO}_{2}$. HT22 cells were starved before stimulation for $8 \mathrm{~h}$ and then stimulated with macrophage colony-stimulating factor (MCSF) (40 ng/ml, ProSpec, East Brunswick, NJ) in a timedependent manner or $24 \mathrm{~h}$. Before the co-culture experiment, BV2 cells were seeded in six-well dishes at $4 \times 10^{4}$ cells/well and transfected with STAT3 siRNAs for $24 \mathrm{~h}$. The cells were washed twice with PBS and then incubated in fresh DMEM containing $10 \%$ FBS after transfection. Then, the HT22 cells were cultured on $0.4 \mu \mathrm{m}$ pore-size Falcon cell culture inserts (Corning, Durham, NC) at $2 \times 10^{5}$ cells/well in DMEM containing 10\% FBS and co-cultured with BV2 cells for $24 \mathrm{~h}$. To confirm the effect of macrophages on neurons, HT22 cells were treated with culture medium of RAW264.7 cells with or without STAT3 inhibition for $24 \mathrm{~h}$.

\section{siRNA Transfection}

BV2 cells and RAW264.7 cells were cultured in the growth condition to a density of $2 \times 10^{5}$ cells in six-well culture plate. The cells were transfected with the siRNAs using HiperFect transfection reagent (Qiagen, Hilden, Germany) according to the fast-forward protocol of manufacturer's instructions. STAT3 siRNAs targeting two different regions of STAT3 (SI01435287 and SI01435294) and a negative control siRNA (1027280) were purchased from Qiagen. 


\section{Immunohistochemistry}

Brains of mice were perfused with buffer containing $4 \%$ paraformaldehyde, fixed for 2 days in $4 \%$ paraformaldehyde at $4{ }^{\circ} \mathrm{C}$, and embedded in paraffin. The paraffin blocks were cut using a microtome $(4 \mu \mathrm{m}$, Finesse E+, Thermo Shandon, Runcom, UK). Paraffin slices were mounted on the silanecoated micro slides (Muto Pure Chemicals, Tokyo, Japan) and then allowed to air dry at room temperature in the dark for $24 \mathrm{~h}$. Before immunostaining, the slides were deparaffinized in xylene, dehydrated through graded alcohols, and heated in citrate buffer for $10 \mathrm{~min}$. Nonspecific binding was blocked with 5\% normal goat serum (Vector Laboratories, Burlingame, $\mathrm{CA}$ ) in PBS. For immunocytochemistry, cells were grown on a poly-L-lysine-coated $60 \mathrm{~mm}^{2}$ cover glass-bottom dish for $24 \mathrm{~h}$ and rinsed with PBS at room temperature. Then, the cells were fixed with $4 \%$ paraformaldehyde for $10 \mathrm{~min}$ and permeabilized in $0.1 \%$ Triton X-100. Nonspecific binding was blocked with $1 \%$ bovine serum albumin (Bovogen, East Keilor, VIC, AUS) in PBS. The fluorescent immunostaining was performed with the primary antibodies for p-STAT3 (1:200, Cell Signaling Technology, MA), STAT3 (1:200, Abcam, Cambridge, UK), Iba-1 (1:200, Wako, Japan), Iba-1 (1:200, Novus Biologicals, CO), and NeuN (1:200, Merck Millipore, MA), and visualized using Cy3 goat anti-mouse IgG, 488 goat antimouse IgG, Cy3 donkey anti-rabbit IgG (1:200, BioLegend, CA), 488 donkey anti-rabbit IgG (1:200, Abcam), and 488 bovine anti-goat IgG (1:200, Santa Cruz Biotechnology, CA, USA). The slides were mounted with 4',6-diamidino-2phenylindole, and images were collected using the LSM510 program on a confocal microscope (Carl Zeiss MicroImaging, München, Germany).

\section{Restraint Stress Procedure}

Mice were transferred to a behavior analysis test room before initiating chronic stress procedures. For the chronic stress, the experimental group was immobilized in a rodent restrainer $(\varnothing 30 \times 95 \mathrm{~mm})$ and separated from the control group for the duration ( $2 \mathrm{~h}$ a day for 14 consecutive days). After the chronic restraint stress, the mice were returned to their home cages for a day and then behavioral experiments were conducted.

\section{Behavioral Experiments}

Behavioral experiments were performed independently according to the behavioral test paradigm and separate groups were used for each behavioral test paradigm.
Experimental mice were subjected to tail suspension and forced swimming tests at intervals of 1 day after 14 days of chronic restraint stress to assess despair-based behavior. A separate cohort of mice was used to conduct sucrose preference test to assess reward-based behavior under normal and chronic stress conditions. Another group was used to assess behavior based on anxiety and locomotion; the following series of behavioral experiments were conducted at intervals of 2 days: handling, elevated plus maze test, openfield test, and rotarod test. All mice were killed immediately after the behavioral experiment and all brain tissues of the mice used in the behavioral experiments under chronic restraint stress were extracted.

\section{Forced Swim Test}

The forced swim test was performed as described previously (Page et al, 1999). Briefly, mice were placed in a glass beaker (2 1 beaker), which was filled to a depth of $18 \mathrm{~cm}$ with water $\left(25^{\circ} \mathrm{C}\right)$. The water was regularly changed between subjects. The duration of immobility was recorded and measured with a video camera for $6 \mathrm{~min}$.

\section{Tail Suspension Test}

Mice were suspended by their tails from a steel bar using adhesive tape in a chamber with opaque walls. The distance between the floor of the chamber and the steel bar was $\sim 40 \mathrm{~cm}$. Mice that climbed onto their tails or fell off during the test were excluded from analyses. Mice movements were videotaped for $6 \mathrm{~min}$ and the total duration of immobility recorded.

\section{Sucrose Preference Test}

The sucrose preference test was conducted as described previously (Strekalova et al, 2004). After food and water deprivation for $24 \mathrm{~h}$, mice were given free access to both water and $1 \%$ sucrose solution in individual cages for $24 \mathrm{~h}$. The position of each bottle was switched after $12 \mathrm{~h}$ to rule out side preference. The consumption of water and sucrose solution was measured by weighing the bottles. The preference for sucrose solution was calculated as a percentage of the volume of consumed sucrose solution over the total volume of liquid drunk.

\section{Open-Field Test}

Mice were placed in the center of an open field box $(40 \times 40 \times 40 \mathrm{~cm})$, illuminated by the light of $20 \mathrm{~lx}$ intensity,

\footnotetext{
Figure I Targeting signal transducer and activator of transcription 3 (STAT3) in microglia by using STAT3 ${ }^{\mathrm{f} / f 1} ;$ LysM-Cre $^{+/-}$mice. (a) Schematic

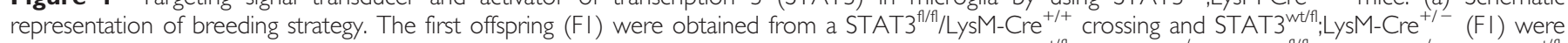

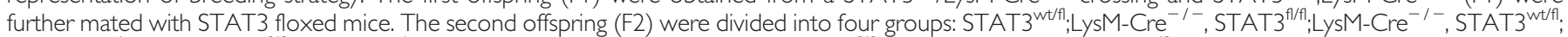
Lys M-Cre $^{+/-}$, and STAT3 ${ }^{f / f / f} ;$ LysM-Cre $^{+/-}$. (b) PCR analysis of STAT3 floxed (STAT3 $\left.{ }^{f / f}\right)$, wild-type (WT) (STAT3 $3^{\text {wt/fl }}$ ) and Cre genes in the second offspring. (c) Immunofluorescence staining for STAT3 (red), Iba-I (green) and 4',6-diamidino-2-phenylindole (DAPI; blue) was performed in the prefrontal cortex (PFC) of the WT and knockout (KO) mice. Scale bar $=40 \mu \mathrm{m}$. Scale bar of the enlarged image $=10 \mu \mathrm{m}$. The graph shows intensity profiles illustrating STAT3/lba- I co-localization measurements. (d) Immunocytochemistry for STAT3 (green) and Iba-I (red) was performed in the primary microglia cells of the WT and KO mice. Scale bar $=50 \mu \mathrm{m}$. (e) The relative immunofluorescence intensity was used to represent protein levels of STAT3 and lba-I (STAT3; I $\pm 0.058 \mathrm{vs}$ $0.245 \pm 0.02 \mathrm{I}$, Iba- I; I \pm 0.075 vs $0.974 \pm 0.054$ in primary microglia of the WT and KO mice, $n=3$ mice/group, respectively). (f) Western blot analysis of STAT3, Iba- I, PSD95, and GFAP in primary microglia, neurons, and astrocytes of the WT and KO mice. Data are means \pm SEM, and * $p<0.05$, ** $p<0.01$, and **** $p<0.00$ I. Representative data from three independent experiments are shown.
} 
and the mice movements were recorded with a video camera for $30 \mathrm{~min}$. The total distance traveled and time spent in the center of the entire open field $(20 \times 20 \mathrm{~cm})$ were calculated using video tracking software (EthoVision XT 8.5, Noldus).

a

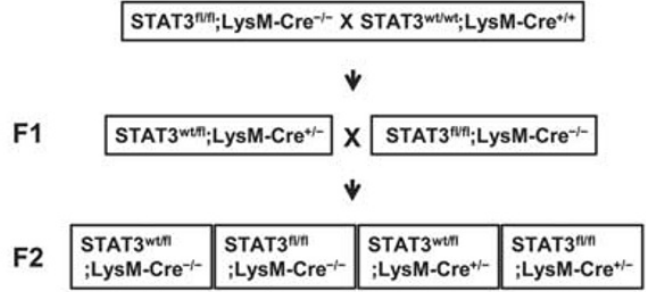

C
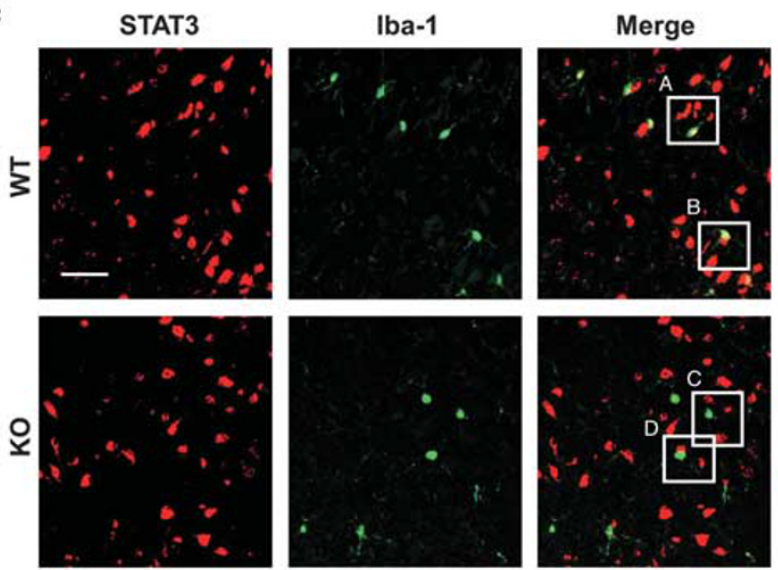

d
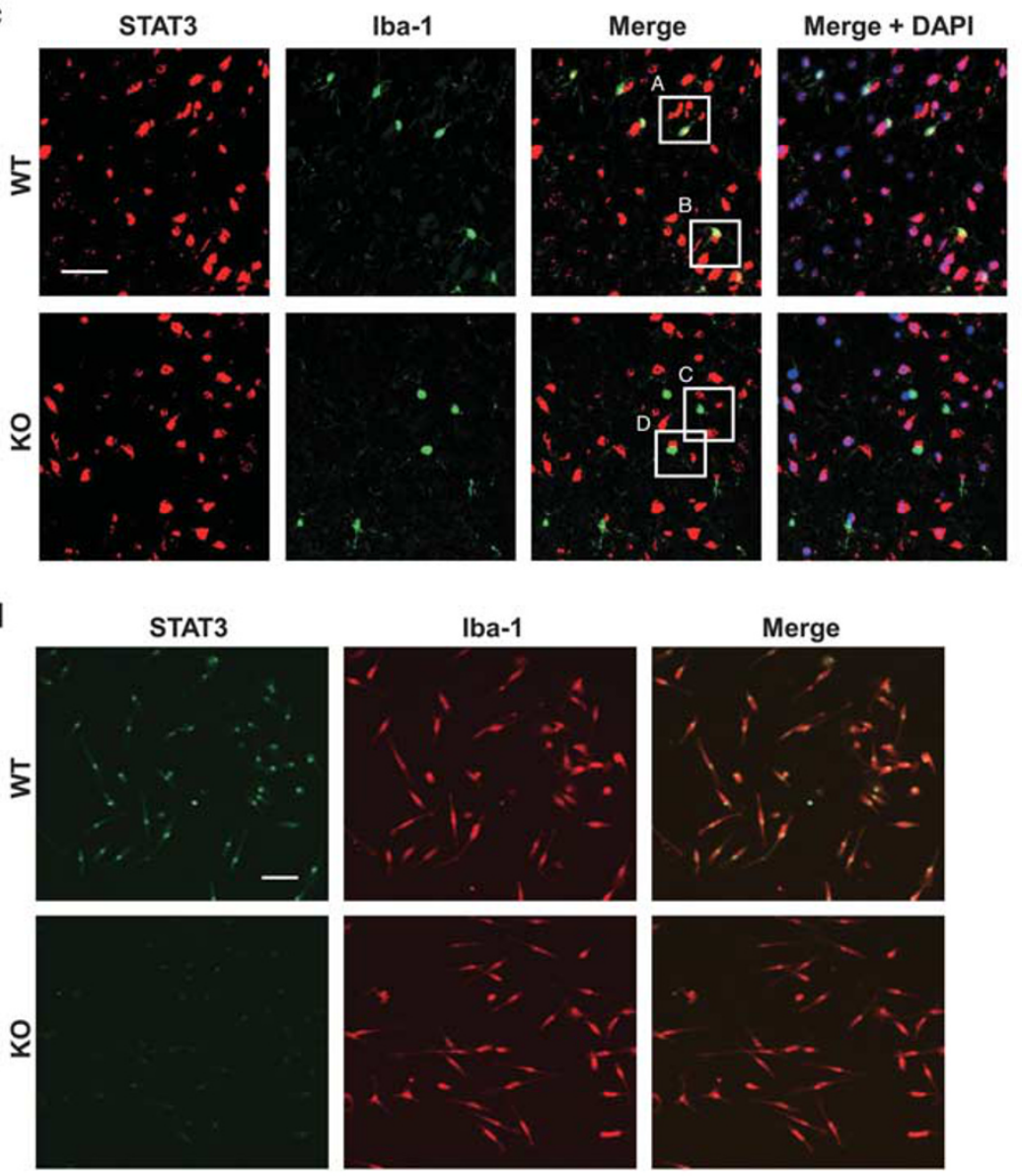
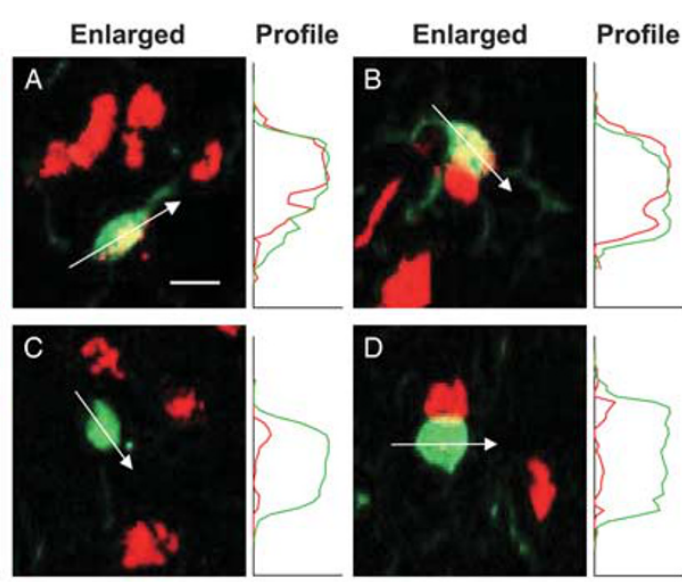

e

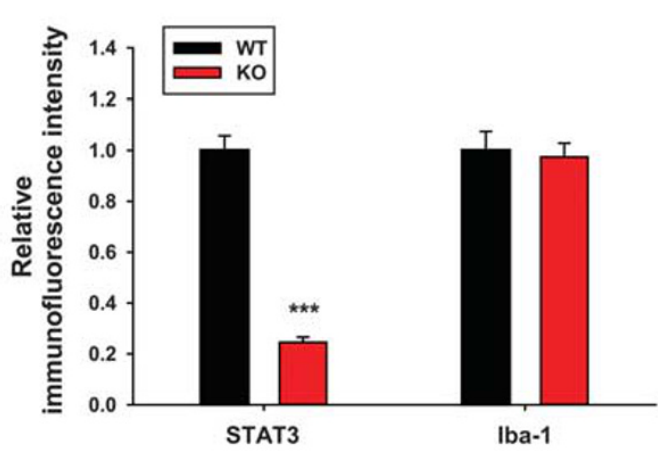

The elevated plus maze consisted of two open arms $(30 \times 5 \mathrm{~cm})$ and two closed arms of the same size, with

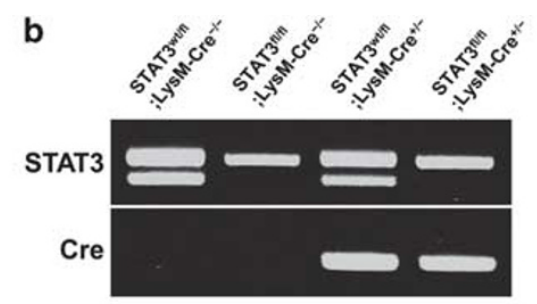

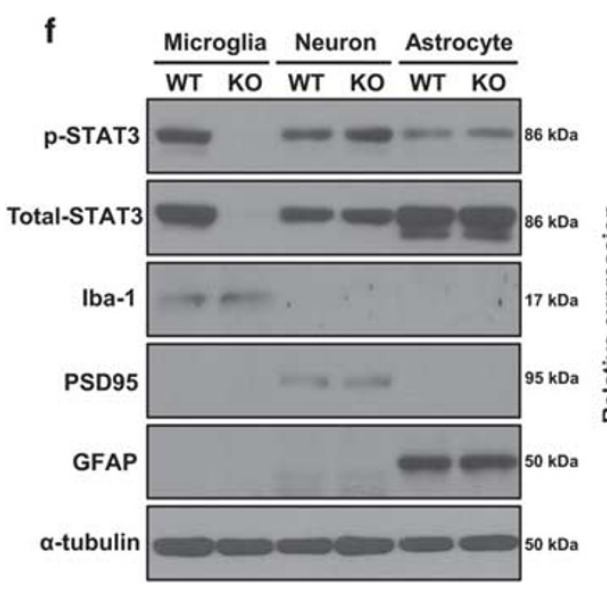
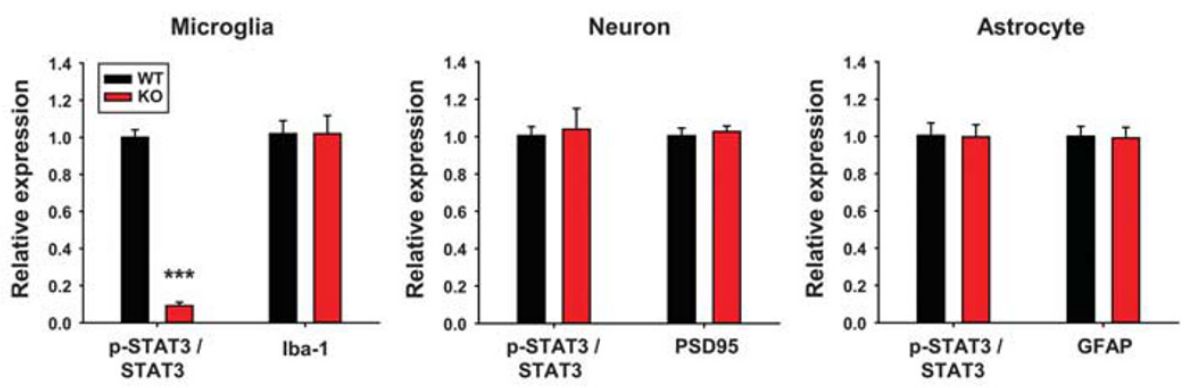
$50 \mathrm{~cm}$ above the ground. Mice were placed in the central square of the maze $(5 \times 5 \mathrm{~cm})$, facing the open arms. The mice movements were recorded during a 5 min test period. The number of entries and the time spent in the open and closed arms were calculated using video tracking software (EthoVision XT 8.5, Noldus).

\section{Rotarod Test}

The rotarod test was performed by a coordination test system (Rotamex 5, Columbus). The mice were placed on a rotating rod $(3 \mathrm{~cm}$ in diameter) accelerated from 3 to $50 \mathrm{rpm}$ for $6 \mathrm{~min}$.

\section{Cytokine Array and Enzyme-Linked Immunosorbent Assay (ELISA)}

The expression of cytokines and chemokines in the culture supernatant was assessed with a mouse cytokine antibody array panel A (R\&D Systems, MN) according to the manufacturer's instructions. Total M-CSF in the conditioned medium of the cultured cells was measured using the quantikine ELISA kit (R\&D Systems) according to the manufacturer's instructions. The data were presented as absorbance units at $450 \mathrm{~nm}$ and correction absorbance units at $540 \mathrm{~nm}$ from three independent experiments.

\section{RNA Isolation and Quantitative Real-Time PCR}

Total RNA was isolated from BV2 and HT22 cells using an RNAiso Plus reagent (Takara, Shiga, Japan) and cDNA was synthesized using ReverTra Ace qPCR RT Master Mix (TOYOBO, Osaka, Japan). Quantitative real-time PCR was performed using the EvaGreen qPCR Mastermix (Applied Biological Materials), and the results were normalized to the signals of GAPDH expression. Primers for CCL2 (QT00167832), STAT3 (QT00148750), ICAM-1 (QT00155078), TNF- $\alpha$ (QT00 104006), IL-1 $\beta$ (QT01048355), IL-6 (QT00098875), IL-10 (QT00 106169), M-CSF (QT01164324), and GAPDH (QT01658692) were purchased from Qiagen.

\section{Western Blotting}

Cells were washed with the cold PBS and then lysed in the Triton lysis buffer containing $1 \%$ Triton X-100, $50 \mathrm{mM}$ Tris-HCl ( $\mathrm{pH} 7.4$ ), $0.35 \mathrm{M} \mathrm{NaCl}, 0.5 \%$ Nonidet P-40, $10 \%$ glycerol, $0.1 \%$ SDS, $1 \mathrm{mM}$ EDTA, $1 \mathrm{mM}$ EGTA, $0.2 \mathrm{mM}$ $\mathrm{Na}_{3} \mathrm{VO}_{4}, 1 \mathrm{mM}$ PMSF, and $0.5 \mathrm{mM} \mathrm{NaF}$. Brain tissue was homogenized and lysed in the triton lysis buffer. After incubation for $30 \mathrm{~min}$ on ice, insoluble debris was removed by centrifugation at $16000 \mathrm{~g}$ for $10 \mathrm{~min}$ at $4{ }^{\circ} \mathrm{C}$. The lysates were resolved in SDS-polyacrylamide gel electrophoresis and transferred to nitrocellulose membranes (GE Healthcare, Pittsburgh, PA). The membranes were blocked in 5\% skim-milk (LPS Solutions, Daejeon, Korea) and probed with the primary antibodies for phospho-STAT3, STAT3, phospho-ERK1/2, ERK1/2, phospho-Akt, Akt (1:1000, Cell Signaling Technology), brain-derived neurotrophic factor (BDNF), phospho-GSK3 $\beta$, GSK3 $\beta$ (1:1000, Santa Cruz Biotechnology), $\alpha$-tubulin (1:1000, Thermo Scientific, Grand Island, NY), VGLUT1, PSD95 (1:2000, 1:1000, Synaptic Systems, Göttingen, Germany), Synaptophysin (1:1000, Epitomics, Burlingame, CA), GFAP (DAKO, CA), and Iba-1 (Novus Biologicals) for the target molecules, followed by HRP-conjugated secondary antibodies for goat anti-mouse IgG, goat anti-rabbit IgG (1:10 000, Enzo Life Science, NY), and donkey anti-goat IgG (1:10 000, Santa Cruz Biotechnology). The membranes were visualized using an ECL detection kit (SurModic, Eden Prairie, MN).

\section{Slice Preparation and Electrophysiology}

Mice were anesthetized with isoflurane and decapitated, and the brains were immediately removed and placed in ice-cold slicing solution $\left(0-4{ }^{\circ} \mathrm{C}\right)$ containing the following artificial cerebrospinal fluid: $124 \mathrm{mM} \mathrm{NaCl}, 2.5 \mathrm{mM} \mathrm{KCl}, 1 \mathrm{mM}$ $\mathrm{NaH}_{2} \mathrm{PO}_{4}, 1.3 \mathrm{mM} \mathrm{MgCl}, 2.5 \mathrm{mM} \mathrm{CaCl}, 26.2 \mathrm{mM} \mathrm{NaH}-$ $\mathrm{CO}_{3}$, and $20 \mathrm{mM}$ D-glucose, bubbled with a gas mixture of $5 \% \mathrm{CO}_{2} / 95 \% \mathrm{O}_{2}$ to maintain a $\mathrm{pH}$ of 7.4. Coronal slices containing medial prefrontal cortex (mPFC) were obtained using a Vibratome (slice thickness $250 \mu \mathrm{m}$; Leica VT1200S; Leica, Nussloch, Germany). After cutting, the slices were kept for $30 \mathrm{~min}$ at $35^{\circ} \mathrm{C}$ and stimulated with M-CSF (10 nM) for synaptosomal preparations and whole-cell recordings. Whole-cell recordings in the mPFC pyramidal cells were performed in the voltage-clamp mode using an amplifier (HEKA Instruments, Lambrecht/Pfalz, Germany). The signal was acquired at $10 \mathrm{kHz}$ and low-pass filtered at $5 \mathrm{kHz}$. For recording the spontaneous miniature excitatory postsynaptic currents (mEPSCs), the recording electrodes (resistance 2-4 M ) were filled with a solution containing (in $\mathrm{mM}$ ) $135 \mathrm{mM}$ Cs-methane sulfonate, $10 \mathrm{mM} \mathrm{CsCl}, 10 \mathrm{mM}$ HEPES, $4 \mathrm{mM} \mathrm{Mg} 2 \mathrm{ATP}, 0.4 \mathrm{mM} \mathrm{Na} 3 \mathrm{GTP}$, and $0.2 \mathrm{mM}$ EGTA (pH 7.25). Synaptic responses were analyzed by Mini Analysis Program, Synaptosoft.

Figure 2 Loss of microglial signal transducer and activator of transcription 3 (STAT3) leads to antidepressive-like behavior. (a) Under control or chronic restraint stress conditions, immobility time of the wild-type (WT) and knockout (KO) mice was assessed by tail suspension test (Control; I $48.943 \pm 9.943 \mathrm{~s}$ vs $103.537 \pm 13.837 \mathrm{~s}, n=12$ and II, Stress; $198.208 \pm 8.490 \mathrm{~s}$ vs $124.013 \pm 13.878 \mathrm{~s}$ in the WT and KO mice, $n=9$ and I0, respectively). (b) Under control or chronic restraint stress conditions, immobility time of the WT and KO mice was assessed by forced swim test (Control; II5.945 $\pm 9.695 \mathrm{~s}$ vs $65.678 \pm 10.593 \mathrm{~s}, n=10$ and II, Stress; $197.328 \pm 9.733 \mathrm{~s}$ vs $131.727 \pm 16.008 \mathrm{~s}$ in the WT and KO mice, $n=9$ and I0, respectively). (c) Preference for sucrose under control or chronic restraint stress conditions (Control; $75.776 \pm 1.914 \%$ vs $77.061 \pm 1.943 \%$, Stress; $55.13 \pm 4.146 \%$ vs $75.833 \pm 2.341 \%$ in the $\mathrm{WT}$ and $\mathrm{KO}$ mice, $n=10$ and 9, respectively). (d) Total liquid intake under control or chronic restraint stress conditions (Control; 4.9 I $\pm 0.1 \mathrm{I9} \mathrm{ml}$ vs $4.95 \pm 0.092 \mathrm{ml}$, Stress; $5.24 \pm 0.121 \mathrm{ml}$ vs $5.1 \pm 0.097 \mathrm{ml}$ in the WT and $\mathrm{KO}$ mice, $n=10$ and 9 , respectively). (e) Total distance (I I $794.746 \pm 81 \mathrm{I} .65 \mathrm{I} \mathrm{cm}$ vs

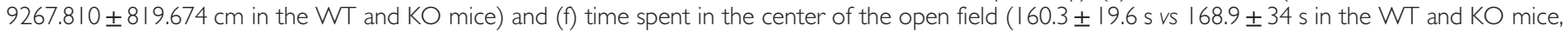
$n=8$ and 9 , respectively). (g) Time spent in the open arms of plus arms ( $133.6 \pm 17.5 \mathrm{~s}$ vs $150.4 \pm 30.2 \mathrm{~s}$ in the WT and KO mice, $n=8$ and 9 , respectively). (h) Total running time on the rotating drum ( $n=8$ and 9 , respectively). Data are means \pm SEM, $* p<0.05$, ** $p<0.01$, and $* * * p<0.00$ I compared with WT; ${ }^{\#} p<0.05,{ }^{\# \#} p<0.01$, and ${ }^{\# \# \#} p<0.001$ compared with control. 


\section{Golgi Staining}

Dendritic spine density was analyzed using an FD Rapid GolgiStain Kit (FD Neurotechnologies, Baltimore, MD) was used according to the manufacturer's instructions. In brief, mice were anesthetized with isoflurane and decapitated. The brains were immediately removed, rinsed, and immersed in the impregnation solution, and stored at room temperature for 2 weeks in the dark. The brains were transferred into a solution containing sucrose and stored at room temperature in the dark for at least 3 days. Frozen slices of the brain were cut using a freezing microtome $(100 \mu \mathrm{m}$, Cryotome FE, a

Tail suspension test

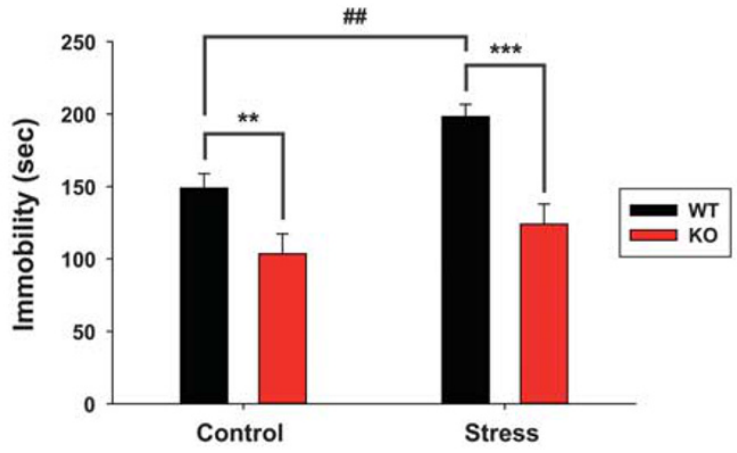

C
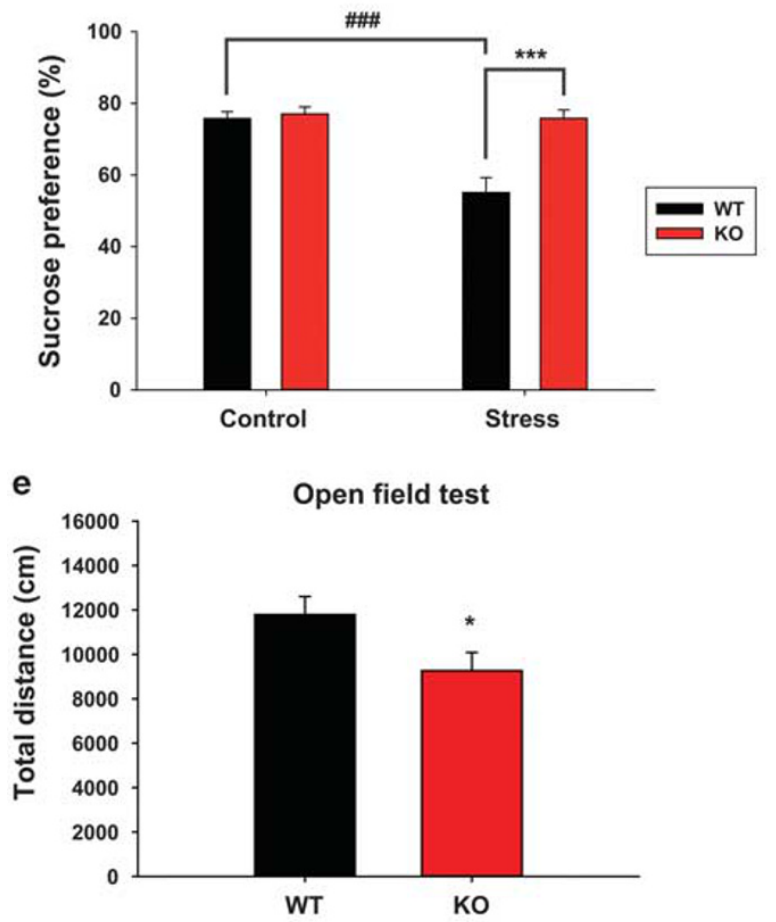

g

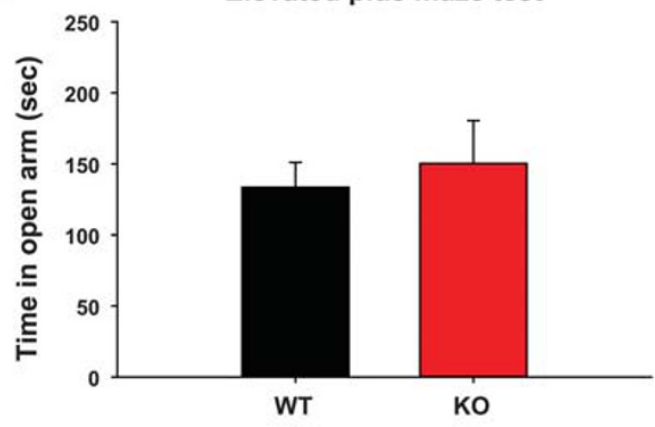

b

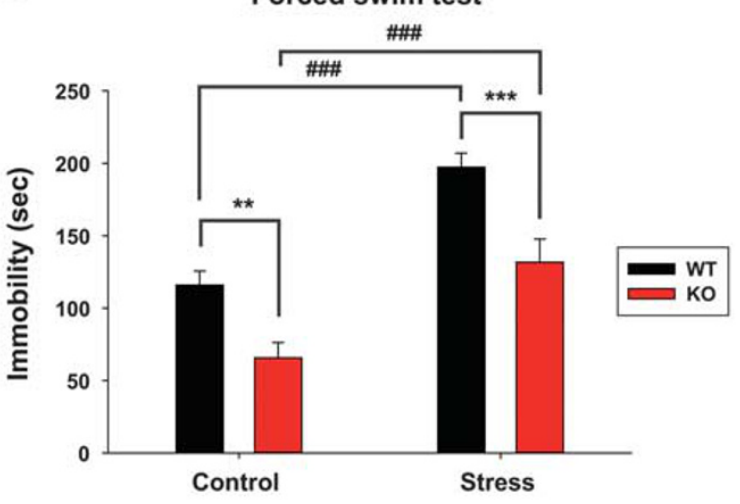

d

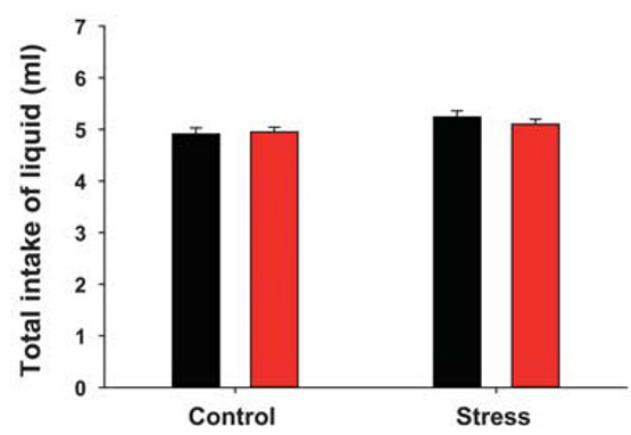

f

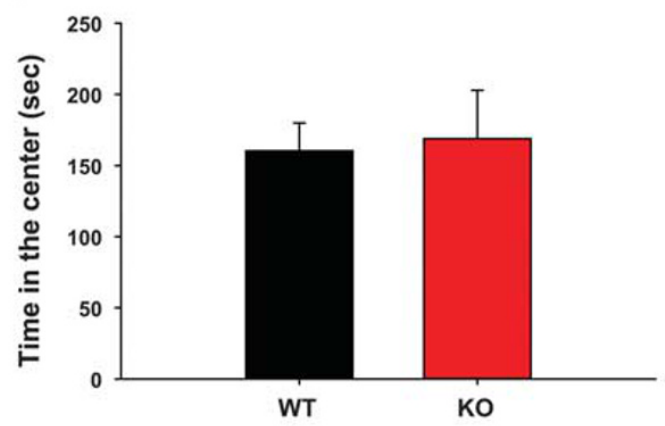

h

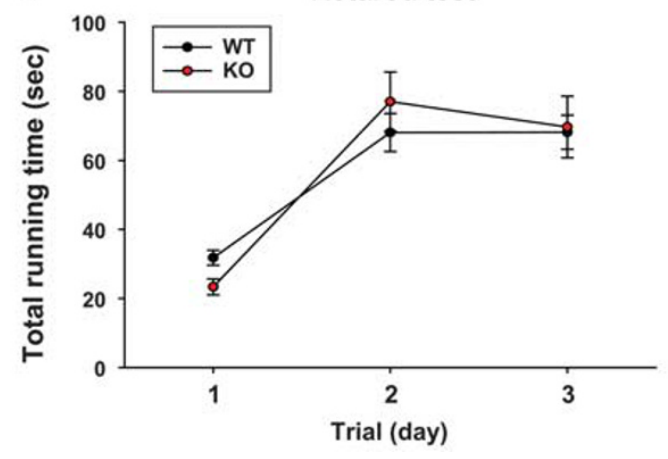


Thermo Shandon). The slices were mounted on gelatincoated microscope slides and then allowed to air dry at room temperature in the dark for 3 days. Slides were then rinsed with distilled water before being dehydrated in absolute alcohol, cleared with xylene, and covered with non-acidic synthetic balsam and cover slips.

\section{Brain Synaptosomal Preparation}

Brain synaptosomal preparation was performed as described previously (Kamat et al, 2014). In brief, the prefrontal cortex was homogenized in $10 \%(\mathrm{w} / \mathrm{v})$ of $0.32 \mathrm{M}$ sucrose-HEPES buffer on ice and the homogenate was centrifuged at $600 \mathrm{~g}$ for $10 \mathrm{~min}$ at $4-8^{\circ} \mathrm{C}$. The HEPES buffer was composed of $145 \mathrm{mM}$ $\mathrm{NaCl}, 5 \mathrm{mM} \mathrm{KCl}, 2 \mathrm{mM} \mathrm{CaCl}, 1 \mathrm{mM} \mathrm{MgCl} 2,5 \mathrm{mM}$ glucose, and $5 \mathrm{mM}$ HEPES ( $\mathrm{pH}$ 7.4). The supernatant was diluted 1:1 with 1.3 M HEPES sucrose, to yield a suspension with a final concentration of $0.8 \mathrm{M}$ HEPES sucrose. This suspension was further centrifuged at three times with HEPES buffer at $12000 \mathrm{~g}$ for $15 \mathrm{~min}$ at $4^{\circ} \mathrm{C}$. The pellet consisting of synaptosomes was suspended in RIPA buffer (mixed with a protease inhibitor and PMSF) along with $0.2 \%$ TritonX-100 and centrifuged at $20000 \mathrm{~g}$ for $30 \mathrm{~min}$. The resulting synaptosomes were immediately used for the western blotting.

\section{Statistical Analysis}

One-way analysis of variance (ANOVA) was used for the statistical analysis of cytokine array. Multiple comparisons were investigated via Tukey-Kramer's post hoc test. Two-way ANOVA (genotype $\times$ stress) was applied to assess behavioral experiments with chronic restraint stress. Bonferroni's post hoc test was performed if applicable. Repeated-measures ANOVA (genotype $\times$ trial session) was used to analyze locomotive activity, and learning and memory. Group comparisons of immunofluorescence intensity, RNA and protein expressions, and electrophysiology data were performed by Student's $t$-tests. The data were assessed to ensure normality with the ShapiroWilk test, and where violations of the normality assumptions were found, non-parametric statistics were conducted. All data are presented in means \pm SEM. All statistical analyses were conducted using SigmaPlot software (ver. 13, Systat Software, San Jose, CA).

\section{RESULTS}

\section{Targeting STAT3 in Microglia by Using STAT3 ${ }^{\mathrm{fl} / \mathrm{fl}}$;LysM- $\mathrm{Cre}^{+/-}$Mice}

Microglia are unique glial cells derived from common myeloid progenitors during developmental stages of the
CNS, possibly explaining the experimental paradigm for neuron-microglia interactions. In this study, we targeted STAT3 in microglia, a key transcription factor for immune responses, due to its relevance in the regulation of cytokine expression levels. We employed the myeloid cell-specific STAT3-deficient mouse model by breeding STAT3 floxed mice and LysM-Cre mice. We denoted STAT3 ${ }^{\mathrm{wt} / \mathrm{fl}} ; \mathrm{LysM}-$ $\mathrm{Cre}^{+/-}$as wild-type (WT) and STAT3 ${ }^{\mathrm{fl} / \mathrm{fl}} ; \mathrm{LysM}^{-C r e^{+/}-}$as KO (Figure 1a; see Materials and Methods).

To verify a STAT3 depletion in microglia, STAT3 gene KO was first confirmed by genotyping (Figure 1b). The absence of microglial STAT3 expression (red, anti-STAT3; green, antiIba-1) in the prefrontal cortex of STAT3 ${ }^{\text {fl/fl }}$ LysM-Cre $^{+/-}$mice was verified using tissue immunostaining. The profile of immunofluorescence intensity showed that STAT3 was not expressed in microglia (Figure 1c). In primary cultured microglial cells (red, anti-Iba-1) obtained from the STAT3deficient mouse model, the expression of STAT3 (green, anti-STAT3) was completely depleted in STAT3 ${ }^{\mathrm{fl} / \mathrm{fl}}$; LysM-Cre $^{+/}$mice, as well as shown in quantitative data (Figures 1d and e; $p<0.001$ ). From the immunoblotting analysis, we also confirmed that the STAT3 expression was depleted specifically in microglia, but not in neurons and astrocytes that were isolated from each primary cultured cell (Figure 1f; $p<0.001$ ). In addition, depletion of STAT3 in microglia had no effect on the expression of STAT3 in neurons and on the number of both neurons and microglia in $\mathrm{STAT}^{\mathrm{fl} / \mathrm{fl}} ; \mathrm{LysM}^{-C r e}{ }^{+/-}$mice (Supplementary Figure S1).

\section{Loss of Microglial STAT3 Leads to Antidepressive-Like Behavior}

To investigate the behavioral correlates of neuron-microglia interactions, we examined mood-related behaviors in the model mice. Interestingly, we observed antidepressive-like behaviors in the tail suspension test, forced swim test, sucrose preference test, and open-field test. As animal models of stress-induced depression to validate the stressresistant behavior, we induced chronic restraint stress for $2 \mathrm{~h}$ a day for 2 weeks. The level of STAT3 phosphorylation were increased in the WT, but not in STAT3 ${ }^{\mathrm{fl} / \mathrm{fl}}$;ysM-Cre $^{+/-}$mice under chronic stress conditions (Supplementary Figure S2). In the tail suspension and forced swim tests, the immobility time was significantly reduced in STAT3 ${ }^{\mathrm{fl} / \mathrm{fl}} ; \mathrm{LysM}_{\mathrm{L}} \mathrm{Cre}^{+/-}$ mice both in control and in chronic stress conditions (Figure 2a; genotype $\times$ stress interaction: $\mathrm{F}_{(1,38)}=1.443$, $p=0.237$; genotype effect: $\mathrm{F}_{(1,38)}=24.906, p<0.001$; stress effect: $F(1,38)=8.469, p=0.006$, and Figure $2 b$; genotype $\times$ stress interaction: $\mathrm{F}_{(1,36)}=0.415, p=0.523$; genotype effect: $\mathrm{F}_{(1,36)}=23.718, \quad p<0.001$; stress effect: $\mathrm{F}_{(1,36)}=38.4$,

Figure 3 Downregulation of microglial signal transducer and activator of transcription 3 (STAT3) increases neuronal macrophage colony-stimulating factor (M-CSF) levels in neuron-microglia interactions. (a) Expression of cytokines and chemokines in the whole brain of the wild-type (WT) and knockout (KO) mice using cytokine arrays. (b) The bar graph was calculated for each cytokine with mean pixel density. (c) Relative mRNA levels of M-CSF, intracellular cell adhesion molecule-I (ICAM-I), interleukin (IL)- I $\beta$ and tumor necrosis factor (TNF)- $\alpha$ in the prefrontal cortex, (d) cerebellum, and (e) hippocampus. ( $f$ ) Expression of cytokines and chemokines in the peritoneal macrophages of the WT and KO mice using cytokine arrays. (g) The bar graph was calculated for each cytokine with men pixel density. (h) Schematic representation of the co-culture system between BV2 and HT22 cells. (i) Relative mRNA levels of STAT3, M-CSF, ICAM-I, IL-I $\beta$, and TNF- $\alpha$ in BV2 cells, and (j) HT22 cells from the co-culture system was quantified by qRT-PCR. (k) Concentration of M-CSF from the co-cultured medium $(217 \pm 3.4 \mathrm{pg} / \mathrm{ml}$ vs $300 \pm 9 \mathrm{pg} / \mathrm{ml}, \mathrm{n}=8 /$ group, respectively) and (I) the BV2-cultured medium $(29.2 \pm 2.6 \mathrm{pg} / \mathrm{ml} \mathrm{vs} 26.7 \pm 2.2 \mathrm{pg} / \mathrm{ml}$, $\mathrm{n}=3$ /group, respectively) were determined by enzyme-linked immunosorbent assay (ELISA). The whole cytokine array panels are presented in Supplementary Figure SIO. Data are means \pm SEM and $* p<0.05$, $* * p<0.0$ I, and $* * * x<0.001$. Representative data from three independent experiments are shown. 


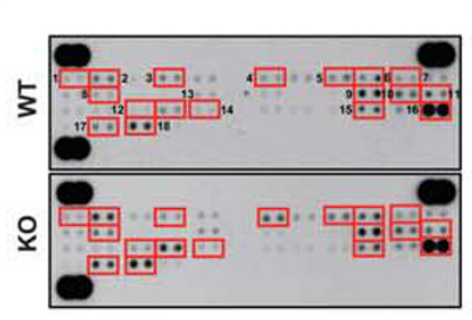

C

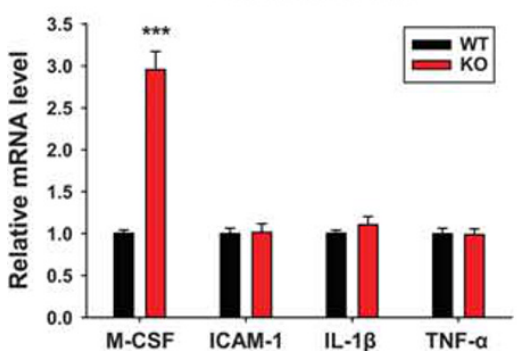

f
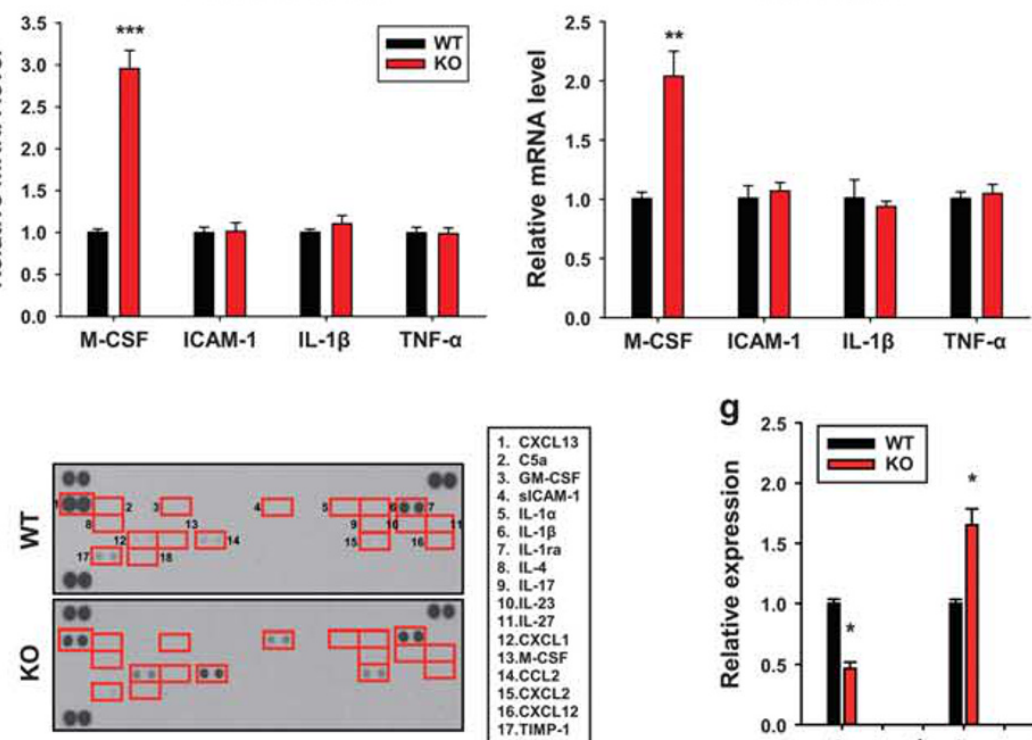

e Hippocampus

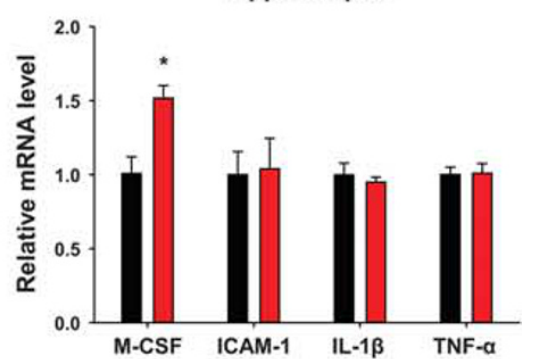

b

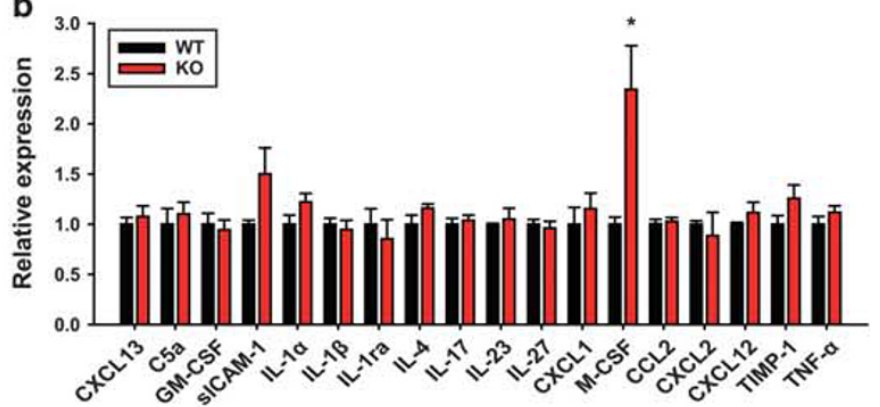

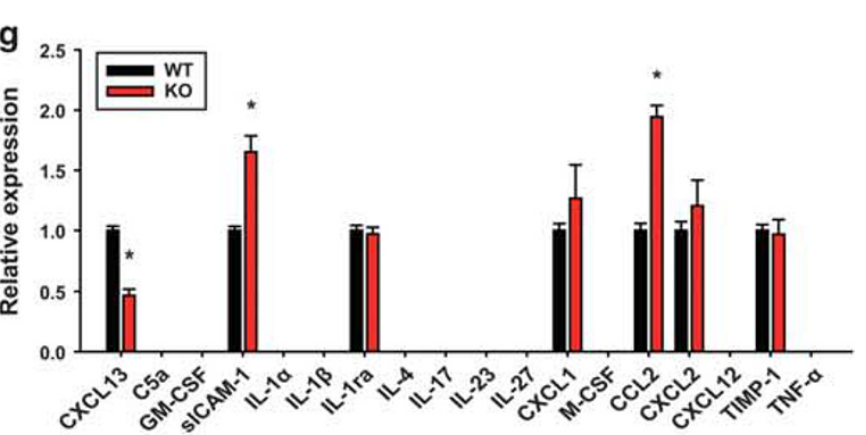

h

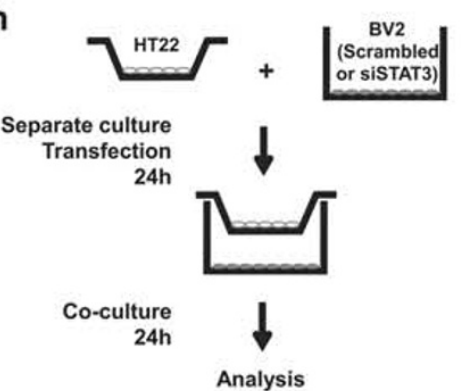

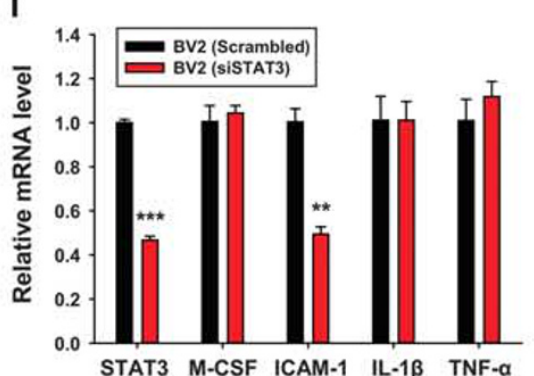
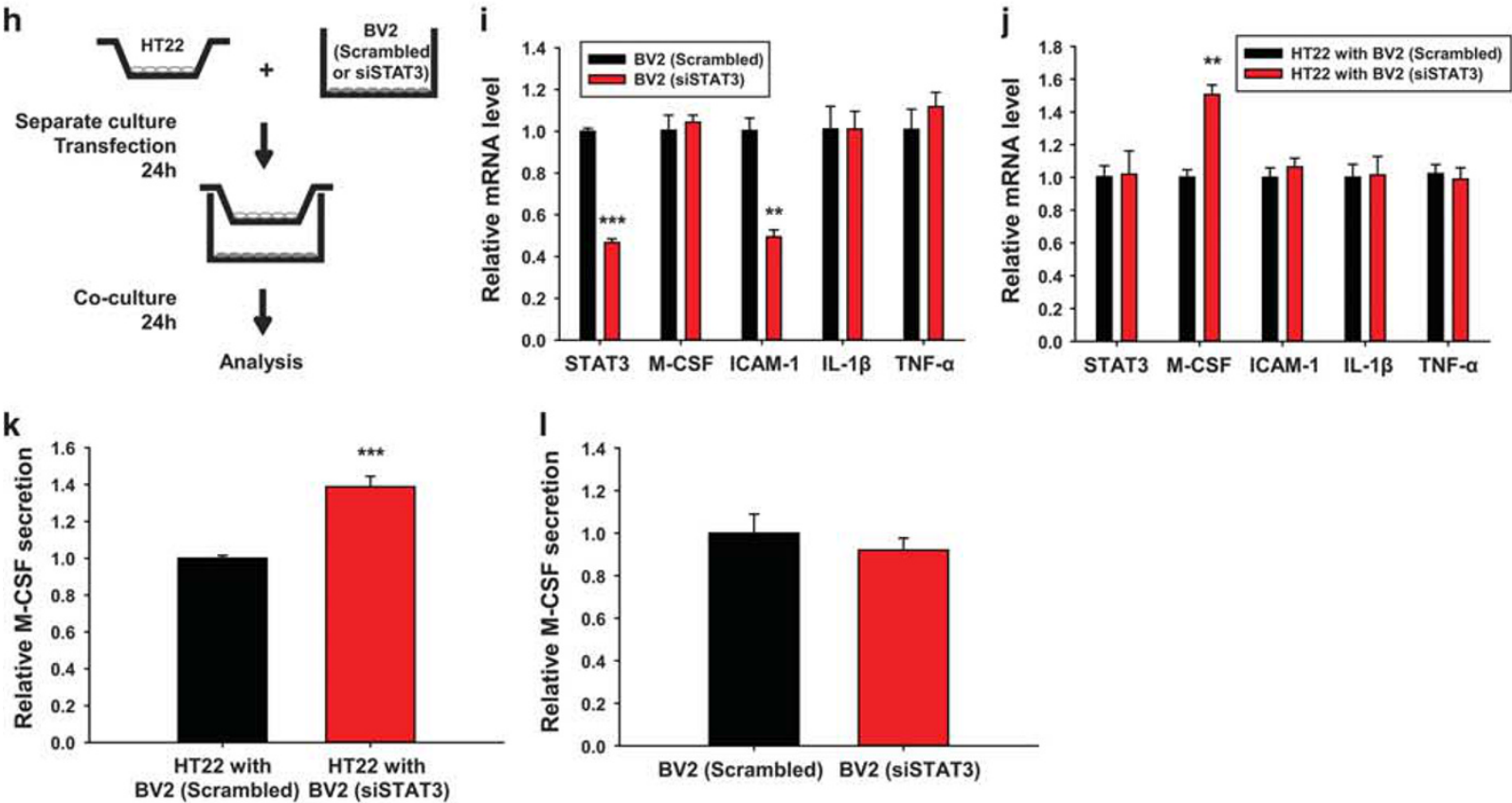
$p<0.001)$. Under chronic stress conditions, the immobility time of STAT3 ${ }^{\mathrm{fl} / \mathrm{fl}} ; \mathrm{LysM}^{-C \mathrm{Cre}^{+/-}}$mice was increased in the forced swim tests, but not in the tail suspension tests (Figure 2b). These results indicate that STAT3 ${ }^{\mathrm{f} / \mathrm{fl}} ;$ LysM$\mathrm{Cre}^{+/-}$mice had intrinsic resistance owing to genetic modification and showed partial resilience to chronic stress conditions. To ensure consistency among WT groups, immobility time was further compared in the tail suspension and forced swim test. The WT groups did not differ from each other (Supplementary Figure S3). Corroborating the generality of these findings, the WT mice subject to chronic restraint stress exhibited a significant decrease in sucrose preference. However, the sucrose preference of $\mathrm{STAT}^{\mathrm{fl} / \mathrm{fl}}$; LysM-Cre $^{+/-}$mice was higher than WT mice under chronic stress conditions (Figure 2c; genotype $\times$ stress interaction: $\mathrm{F}_{(1,35)}=12.295, p=0.001$; genotype effect: $\mathrm{F}_{(1,35)}=15.764$, $p<0.001$; stress effect: $\left.\mathrm{F}_{(1,35)}=15.601, p<0.001\right)$. Both WT and STAT ${ }^{\mathrm{ll} / \mathrm{f}}$; LysM-Cre ${ }^{+/-}$mice showed similar amounts of liquid intake under both control and stressed conditions (Figure 2d; genotype $\times$ stress interaction: $\mathrm{F}_{(1,35)}=0.573$, $p=0.454$; genotype effect: $\mathrm{F}_{(1,35)}=0.177, p=0.677$; stress effect: $\left.\mathrm{F}_{(1,35)}=4.071, p=0.051\right)$. Lastly, we verified reduced

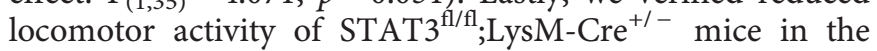
open-field test (Figure 2e; $p<0.05$ ), but not the exploration time in the center area (Figure 2f). A previous study demonstrated that the stressed mice showed enhanced locomotor activity under the light of modest brightness (Strekalova et al, 2004). Our results suggest that antidepressive-like behavior was observed in STAT3 $3^{\mathrm{fl} / \mathrm{fl}}$; LysM-Cre $^{+/-}$mice. Collectively, dysregulation of STAT3 in microglia successfully alleviated depressive and stressinduced behaviors.

In addition, we found no differences in body weight, anxiety-related, and motor behaviors of STAT3 ${ }^{\mathrm{t} / \mathrm{fl}} ; \mathrm{LysM}$ $\mathrm{Cre}^{+-}$mice (Supplementary Figure S4a and Figures $2 \mathrm{~g}$ and $h$; trial session effect: $F_{(2,30)}=83.245, p<0.001$; genotype effect: $\mathrm{F}_{(1,15)}=0.008, p=0.931$ ), demonstrating that deletion of STAT3 in microglia had solely contributed to antidepressive effects. We also tested whether the antidepressive effects could affect other cognitive functions associated with learning and memory, but found neither cognitive impairment nor enhancement in STAT3 ${ }^{\mathrm{fl} / \mathrm{fl}}{ }_{\mathrm{LysM}-\mathrm{Cre}^{+/-}}$mice (Supplementary Figure S4b-f).

\section{Downregulation of Microglial STAT3 Increases Neuronal M-CSF Levels in Neuron-Microglia Interactions}

To identify key factors affecting antidepressive-like behavior caused by depletion of microglial STAT3, we first examined the cytokine levels in the brain tissue of both WT and $\mathrm{STAT}^{\mathrm{f} / \mathrm{fl}} ;$ LysM-Cre ${ }^{+/-}$mice using a cytokine array. The data showed that M-CSF was increased solely in STAT3 $3^{\mathrm{f} / \mathrm{fl}}$; LysM-Cre $^{+/-}$mice (Figures $3 \mathrm{a}$ and $\mathrm{b}$; one-way ANOVA: $\left.\mathrm{F}_{(1,4)}=9.304, p<0.05\right)$. The effect of M-CSF in association with antidepressive-like behavior was highly localized to several brain regions, such as prefrontal cortex, cerebellum, and hippocampus, where M-CSF receptors were primarily expressed (Figure $3 c ; p<0.001$, Figure $3 \mathrm{~d} ; p<0.01$, and Figure 3e; $p<0.05)$. However, we could not detect any change in the levels of canonical cytokines, such as ICAM-1, IL-1 $\beta$, TNF- $\alpha$, IL-6, and IL-10 (Figure 3b and Supplementary Figure S5). These results suggest that M-CSF may be a key factor for regulating antidepressive-like behavior. To determine whether peripheral macrophages had an effect on increasing M-CSF, we applied the same cytokine array to peritoneal macrophages isolated from both WT and STAT3 $^{\mathrm{fl} / \mathrm{fl}} ;$ LysM-Cre $^{+/}$- mice (Figure 3f and Supplementary Figure S6a). sICAM-1 and CCL2 were increased, but CXCL13 was decreased in macrophages of STAT3 ${ }^{\mathrm{fl} / \mathrm{fl}} ;$ LysM$\mathrm{Cre}^{+/-}$mice (Figure 3g; CXCL13: $\mathrm{F}_{(1,2)}=71.092, p<0.05$; sICAM-1: $\mathrm{F}_{(1,2)}=22.346, \quad p<0.05 ; \quad$ CCL2: $\mathrm{F}_{(1,2)}=71.906$, $p<0.05)$. These factors were expressed at the similar level in the brain tissue, indicating that M-CSF-mediated antidepressive-like behavior was not associated with peripheral macrophages. In short, the results indicate that M-CSF production regulates antidepressive-like behaviors through neuron-microglia interactions.

To mimic the neuron-microglia interactions of STAT3 $3^{\mathrm{f} / \mathrm{fl}}$; LysM-Cre $^{+/}$mouse model, we performed in vitro co-culture using transwell inserts with both the neuronal cell line HT22 and the microglia cell line BV2 (Figure 3h). Endogenous STAT3 level was silenced by transfection with specific small interfering RNA for STAT3 (siSTAT3) in BV2 cells with the maintenance of cell viability (Supplementary Figure S6b and c). Although the mRNA level of STAT3 and ICAM-1 in BV2 cells decreased in the co-culture system, the M-CSF, IL- $1 \beta$, and TNF- $\alpha$ levels remained unchanged in the cells (Figure 3i; STAT3: $p<0.001$, ICAM-1: $p<0.01$ ). Importantly, the mRNA level of M-CSF increased in HT22 cells co-cultured with STAT3 knocked-down BV2 cells, but no change was observed in the STAT3, ICAM-1, IL-1 $\beta$, and TNF- $\alpha$ mRNA levels (Figure 3j; $p<0.01$ ).

Based on the results, we hypothesized that the secretion of M-CSF may occur mainly in neuronal cells. To examine this, we measured the concentration of M-CSF using an ELISA in the co-culture system. The amount of secreted M-CSF was highly increased in the co-culture medium of HT22 cells with STAT3-silenced BV2 cells (Figure 3k; $p<0.001$ ); however,

\footnotetext{
Figure 4 Macrophage colony-stimulating factor (M-CSF) upregulates antidepressant signaling pathways and brain-derived neurotrophic factor (BDNF)

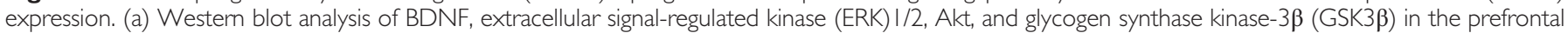
cortex (PFC, ctx), cerebellum (ceb), and hippocampus (hip) of the wild-type (WT) and knockout (KO) mice. (b) Western blot analysis of BDNF, ERKI/2, Akt, GSK3 $\beta$, synaptophysin, PSD95, VGLUTI, GFAP, and Iba-I in the synaptosomes isolated from the PFC of the WT and KO mice. (c) Western blot analysis of ERKI/2, Akt, GSK3 $\beta$, synaptophysin, PSD95, VGLUTI, GFAP and Iba-I in the synaptosomes isolated from PFC slices of the WT mice after a time-dependent M-CSF stimulation (IO nM). (d) Western blot analysis of BDNF, ERKI/2, Akt, and GSK3 $\beta$ in BV2 and HT22 cells from the co-culture set. (e) Western blot analysis of BDNF, ERKI/2, Akt, and GSK3 $\beta$ in HT22 cells after M-CSF stimulation (40 ng/ml) for $24 \mathrm{~h}$. (f) Western blot analysis of ERKI/2, Akt, and GSK3 $\beta$ in HT22 cells after a time-dependent M-CSF (40 ng/ml) stimulation. (g) Western blot analysis of BDNF, ERKI/2, Akt, and GSK3 $\beta$ in HT22 cells treated with RAW264.7 cultured medium with or without STAT3 inhibition. Each quantification of western blotting was obtained with relative densitometry and normalized with $\alpha$-tubulin. Whole western blotting images of BDNF are presented in Supplementary Figure SII. Data are means \pm SEM and $* p<0.05$, *** $p<0.01$, and $* * * *<<0.001$. Representative data from three independent experiments are shown.
} 
a

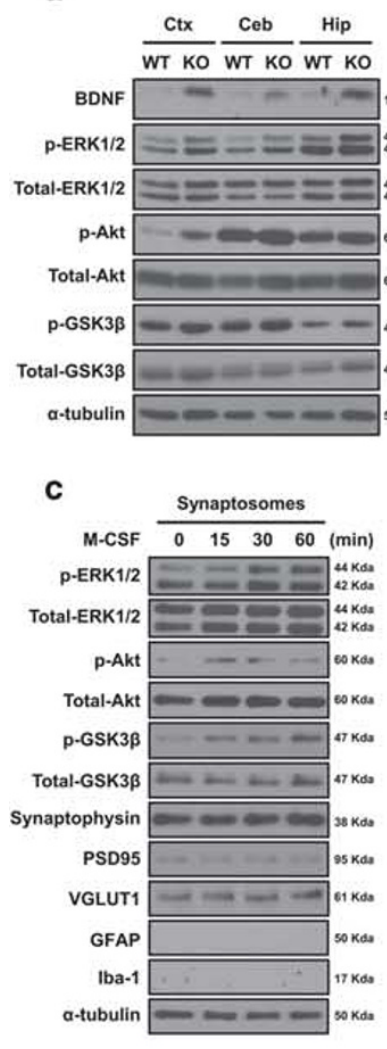

d

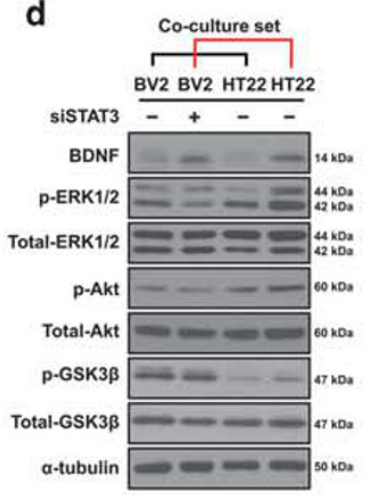

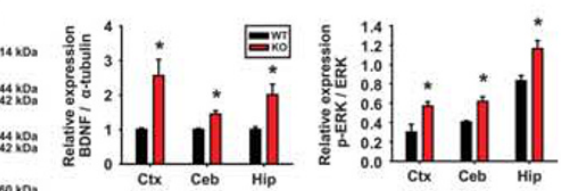
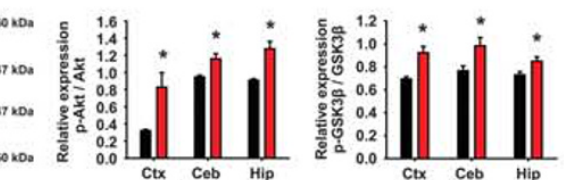

b

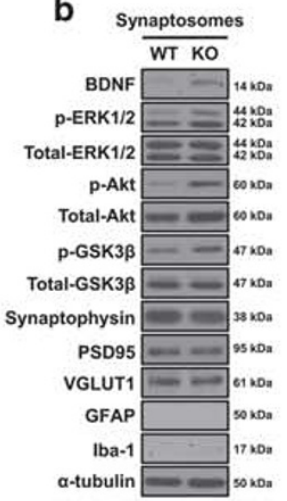

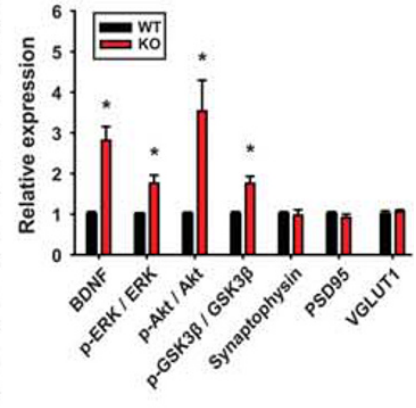
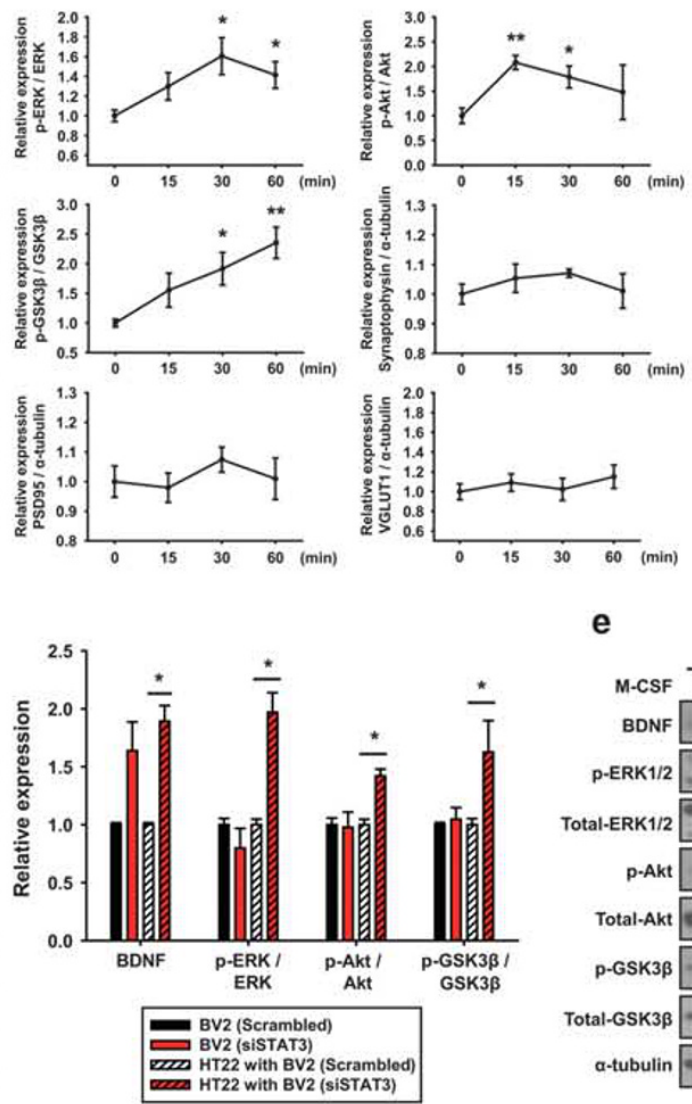

e
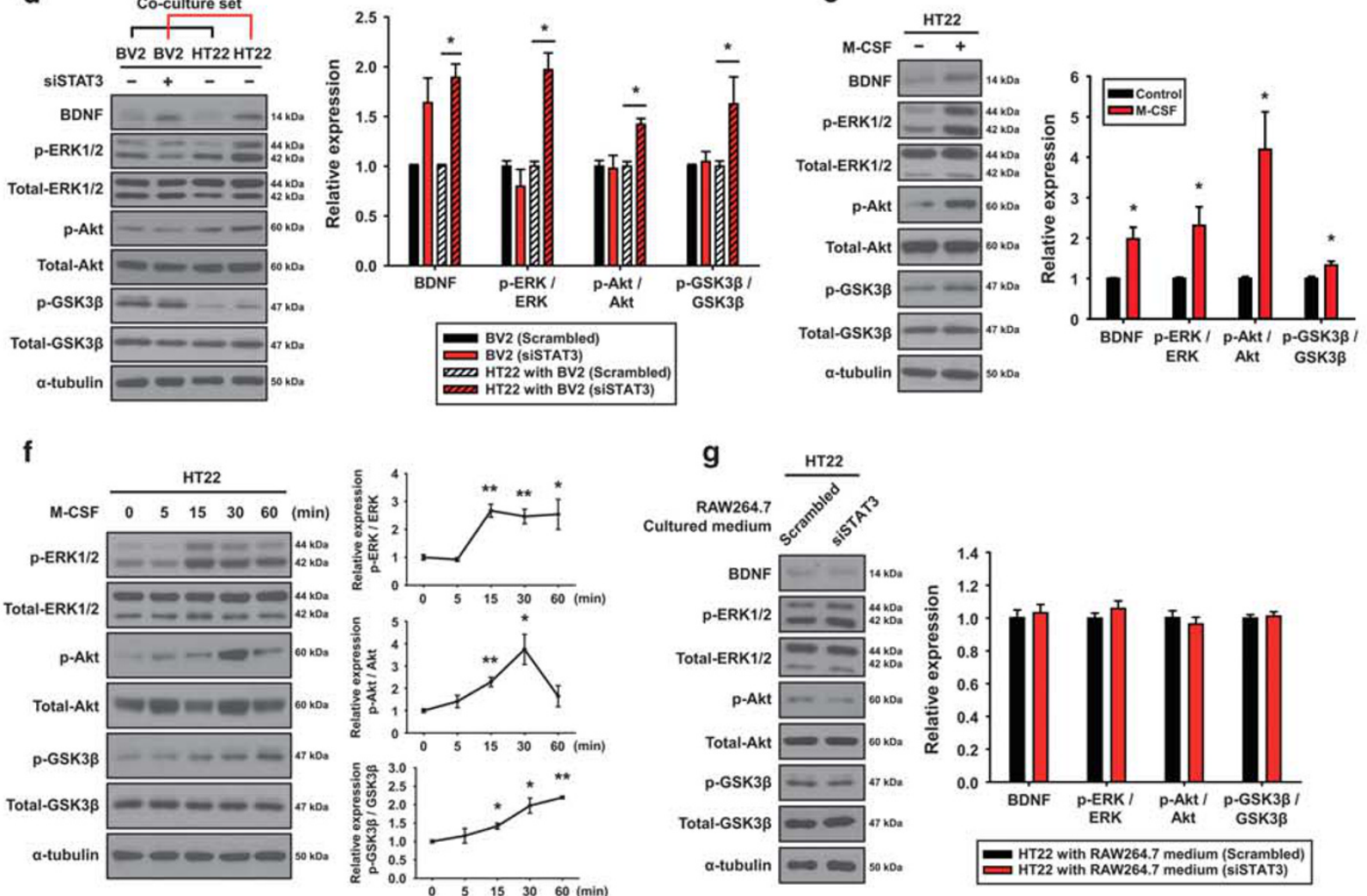
that of M-CSF secretion had no difference between the control and STAT3-silenced BV2 cells (Figure 31). Thus, the data suggest that ablation of STAT3 in microglia is crucial for the increase in M-CSF production in neuronal cells and that these mechanisms may have a crucial role in neuronal functions, leading to the antidepressive-like behavior in $\mathrm{STAT}^{\mathrm{fl} / \mathrm{fl}}{ } \mathrm{LysM}_{\mathrm{L}} \mathrm{Cre}{ }^{+/-}$mice.

\section{M-CSF Upregulates Antidepressant Signaling Pathways and BDNF Expression}

To identify how the secreted M-CSF triggers the activation of antidepressant signaling pathways, we investigated BDNF levels and signaling cascades of ERK $1 / 2$ and Akt/GSK $3 \beta$ in the STAT3 ${ }^{\mathrm{fl} / \mathrm{f}}$; $\mathrm{LysM}-\mathrm{Cre}^{+/-}$mouse model. We observed that the BDNF expression as well as ERK1/2 and Akt/GSK3 $\beta$ phosphorylation were increased in several brain regions of $\mathrm{STAT}^{\mathrm{fl} / \mathrm{fl}} ; \mathrm{LysM}^{-C r \mathrm{C}^{+/-}}$mice, including the prefrontal cortex, cerebellum, and hippocampus (Figure $4 \mathrm{a}$; all $p<0.05$ ). In synaptosomes from the prefrontal cortex of STAT3 ${ }^{\mathrm{fl} / \mathrm{fl}}$; LysM-Cre $^{+/-}$mice, the phosphorylation of ERK1/2 and Akt/GSK3 $\beta$ was enhanced, along with increased BDNF expression; however, we found no changes in the levels of pre-/post-synaptic proteins, such as synaptophysin, VGLUT1, and PSD95 (Figure 4b; all $p<0.05$ ). Lastly, we verified the direct effects of M-CSF on ERK1/2 and Akt/ GSK3 $\beta$ signaling pathways in a time-dependent manner in synaptosomes from cortical slices of the WT mice. M-CSF stimulation gradually increased phosphorylation of ERK1/2 and Akt/GSK3 $\beta$ in synaptic level (Figure $4 \mathrm{c}$; ERK1/2 at 30, $60 \mathrm{~min}$, Akt and GSK $3 \beta$ at $30 \mathrm{~min}: p<0.05$, Akt at $15 \mathrm{~min}$ and GSK $3 \beta$ at $60 \mathrm{~min}: p<0.01)$. The results imply that $\mathrm{M}$-CSF activates antidepressant pathways, along with BDNF production.

We further confirmed the results in in vitro co-culture system. The expression of BDNF as well as phosphorylation of ERK1/2 and Akt/GSK3 $\beta$ was increased only in HT22 cells co-cultured with STAT3-silenced BV2 cells (Figure 4d; all $p<0.05)$. As expected, BDNF expression was persistently increased and both ERK1/2 and Akt/GSK3 $\beta$ remained phosphorylated after M-CSF stimulation for $24 \mathrm{~h}$ in HT22 cells (Figure 4e; all $p<0.05$ ). Finally, we observed the direct effects of M-CSF within an hour on ERK1/2 and Akt/GSK $3 \beta$ signaling pathways in HT22 cells (Figure 4f; ERK1/2 at $60 \mathrm{~min}$, Akt at $30 \mathrm{~min}$, and GSK3 $\beta$ at 15, $30 \mathrm{~min}$ : $p<0.05, \mathrm{ERK} 1 / 2$ at $15,30 \mathrm{~min}, \mathrm{Akt}$ at $15 \mathrm{~min}$, and GSK $3 \beta$ at $60 \mathrm{~min}: p<0.01)$. However, we found no direct effects of peritoneal macrophages on neuronal cells. ERK1/2 and Akt/GSK3 $\beta$ signaling pathways did not induce any change in HT22 cells with macrophage cell line RAW264.7 medium regardless of whether STAT3 was downregulated or not (Figure $4 \mathrm{~g}$ and Supplementary Figure S6d and e). We reasoned that the effects of M-CSF stimulation on microglia should be tested since M-CSF was one of the well-known inducers for intracellular signaling in microglia (Imai and Kohsaka, 2002). Data showed that the phosphorylation of ERK1/2 and Akt/GSK3 $\beta$ did not increase in STAT3-silenced BV2 cells (Supplementary Figure S7). Collectively, our data strongly indicate that M-CSF may be critically involved in antidepressive-like behavior by upregulating BDNF expression through a direct effect on the ERK1/2 and Akt/GSK3 $\beta$ signaling cascades.

\section{Depletion of Microglial STAT3 Enhances M-CSF- Mediated Glutamatergic Neurotransmission}

As neuronal mechanisms of depression, the increased synaptic transmission could be a potent mechanism from a therapeutic point of view (Duman and Aghajanian, 2012a). To explore the microglia-derived effects on neurotransmission, we investigated the excitatory synapses of the pyramidal cells (layer 5 ) in the mPFC by recording $\alpha$-amino-3-hydroxy5-methyl-4-isoxazolepropionic acid (AMPA) receptormediated mEPSCs. As the representative traces demonstrated (Figure 5a), the cumulative probability distributions of the mEPSC frequency increased in STAT3 ${ }^{\mathrm{fl} / \mathrm{f}} ; \mathrm{LysM}_{\mathrm{L}} \mathrm{Cre} \mathrm{C}^{+/-}$ model mice (Figure 5b; $p<0.05$ ); however, those of the mEPSC amplitudes were not statistically different (Figure 5c). These results imply that microglia-derived effects could facilitate the release of neurotransmitters on presynaptic synapses.

The above results led us to further investigate whether M-CSF could affect the release of neurotransmitters on presynaptic synapses. We incubated brain slices with M-CSF for $10 \mathrm{~min}$ and measured the mEPSCs. As the representative traces illustrated (Figure 5d), the cumulative probability distributions of the mEPSC frequency were increased in the presence of M-CSF (Figure 5e; $p<0.05$ ); however, those of the mEPSC amplitudes were not statistically different (Figure 5f).

Furthermore, we investigated whether the increase in the mEPSC frequency caused by M-CSF was involved in the presynaptic effect. By stimulating the layer $2 / 3$ of the mPFC, we measured the paired-pulse ratio in the excitatory synapses of the pyramidal cells (layer 5). As the representative traces illustrated (Figure 5g), the probability of neurotransmitter release was increased in STAT3 ${ }^{\mathrm{fl} / \mathrm{fl}} ; \mathrm{LysM}^{\mathrm{C} C \mathrm{Cre}^{+/-}}$mice (Figures $5 \mathrm{~h}$ and $\mathrm{i}$; all $p<0.01$ ). In addition, we analyzed the shape of individual traces of AMPA receptor-mediated EPSCs, but found no differences in decay time and 10\%-90\% rise time in both STAT3 ${ }^{\mathrm{fl} / \mathrm{fl}}$;LysM-Cre ${ }^{+/-}$model mice and $\mathrm{M}$-CSF treatment group (Supplementary Figure S8). In morphological perspectives, Golgi staining showed no differences in the number of dendritic spines between the $\mathrm{WT}$ and STAT3 ${ }^{\mathrm{fl} / \mathrm{fl}} ; \mathrm{LysM} \mathrm{Cre}^{+/-}$mice (Figures $5 \mathrm{j}$ and $\mathrm{k}$ ). We concluded that elevated M-CSF secretion in neuronal cells caused by interaction with STAT3-deficient microglia presynaptically enhanced glutamatergic neurotransmission.

\section{DISCUSSION}

In the present study, we explored the mechanisms of neuron-microglia interactions. Primarily, we used a microglia-targeted STAT3-deficient mouse model. From an immunological perspective, STAT3 signaling has a major role in immune responses and microglia are CNS-resident immune cells that sense stress in the microenvironment. However, microglia were shown to modulate synaptic activity through functional changes (Wake et al, 2013). In the current study, we demonstrated that dysfunction of STAT3 in microglia enhanced M-CSF action on neural 


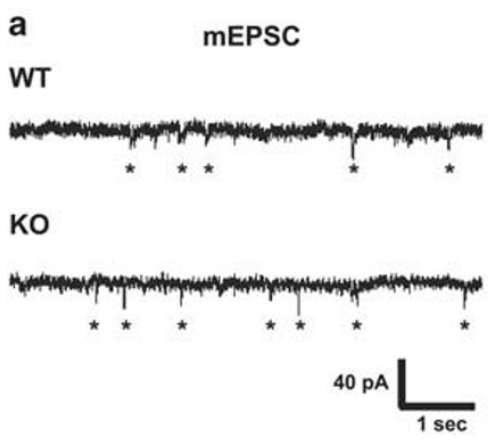

d mEPSC

Control

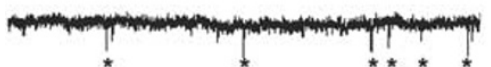

M-CSF (10nM)
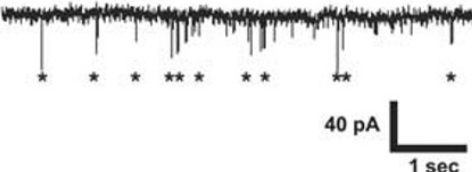

g

WT<smiles>C=CCCCC</smiles>

KO

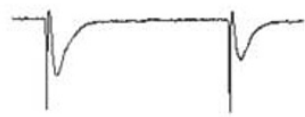

$200 \mathrm{pA} L$

j

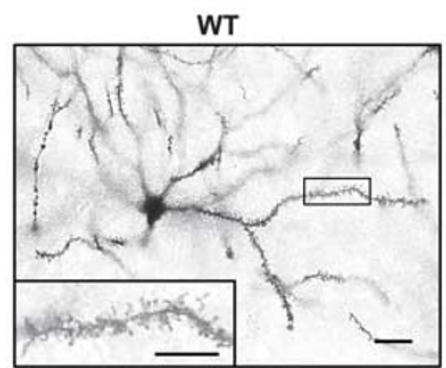

b

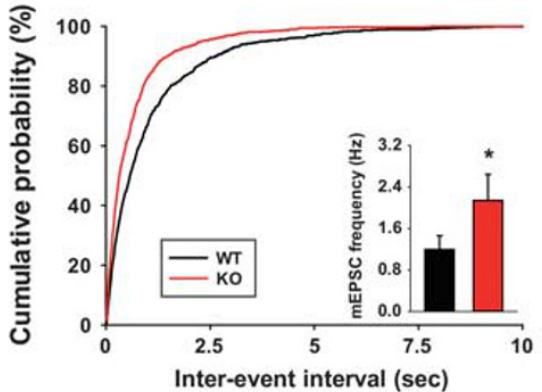

e

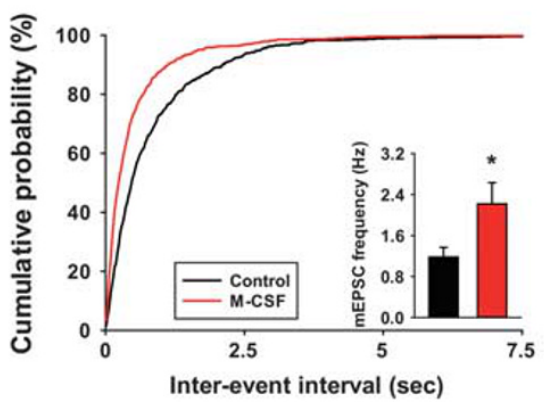

h

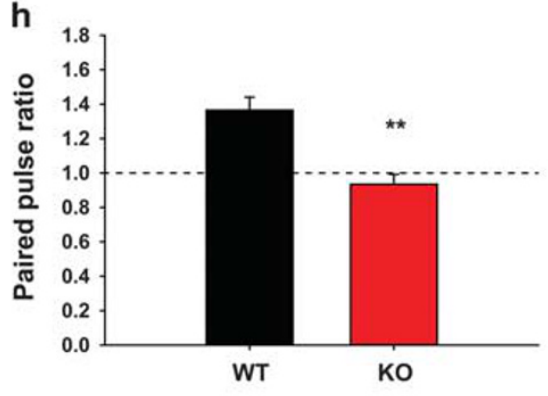

ко

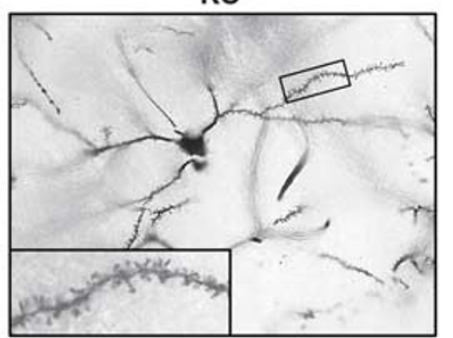

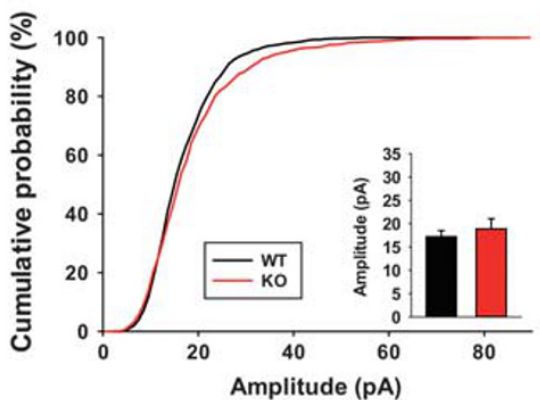

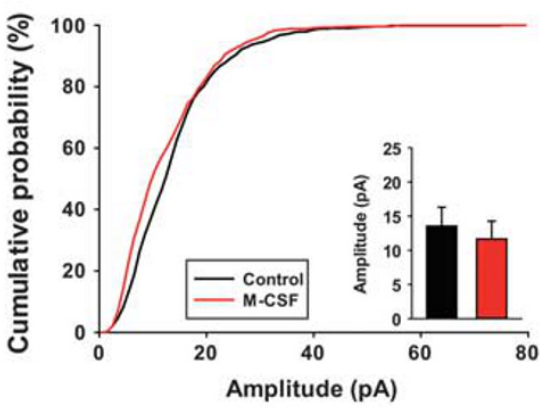

i

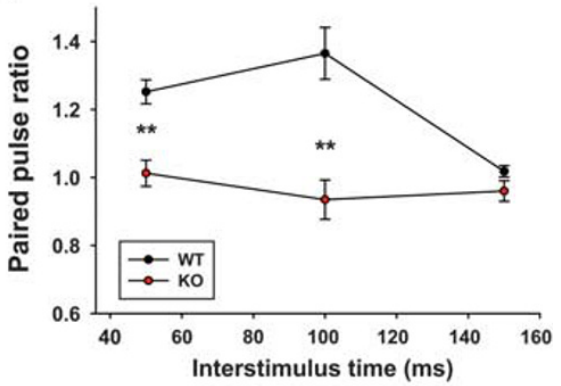

k

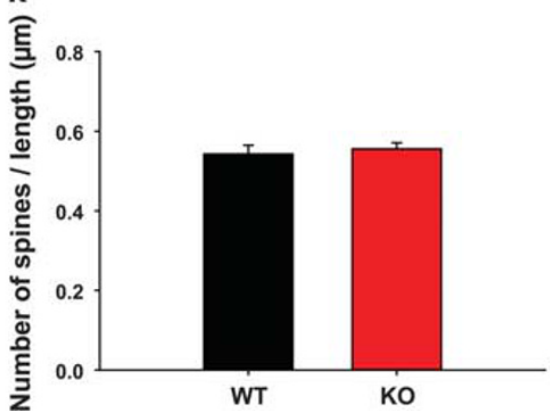

Figure 5 Depletion of microglial signal transducer and activator of transcription 3 (STAT3) enhances macrophage colony-stimulating factor (M-CSF)-mediated glutamatergic neurotransmission. (a) Representative traces of the miniature excitatory postsynaptic currents (mEPSCs) in the wild-type (WT) and knockout (KO) groups ( $n=10$ and 9 neurons/group). Each asterisk indicates synaptic events. (b) Graphs for the cumulative probability of the mEPSC frequency; bar graphs for an average of frequency $(1.2 \pm 0.27 \mathrm{~Hz}$ vs $2.14 \pm 0.5 \mathrm{~Hz}$ in the WT and $\mathrm{KO}$ mice, respectively). (c) Graphs for the cumulative probability of the mEPSC amplitudes; bar graphs for an average of amplitudes (17.185 I I.306 pA vs I8.846 \pm 2. 186 pA in the WT and KO mice, respectively). (d) Representative traces of the mEPSCs in the control and the M-CSF treatment groups ( $n=6$ neurons/group). (e) Graphs for the cumulative probability of the mEPSC frequency; bar graphs for an average of frequency $(1.18 \pm 0.19 \mathrm{~Hz}$ vs $2.22 \pm 0.412 \mathrm{~Hz}$ in the control and M-CSF treatment groups, respectively). (f) graphs for the cumulative probability of the mEPSC amplitudes; bar graphs for an average of amplitudes (I3.538 \pm 2.765 pA vs I I.65 I \pm 2.620 pA in the control and M-CSF treatment groups, respectively). (g) Representative traces for paired pulse ratio measurement in WT and $K O$ mice ( $n=6$ and 5 neurons/group). (h) The graph for paired pulse ratio at the I 00 ms intervals (paired-pulse ratio (PPR): the ratio of EPSC2/EPSCI) ( $1.365 \pm 0.076$ vs $0.935 \pm 0.058$ in the WT and KO mice, respectively). (i) Dependence of PPR on interstimulus intervals at the 50,100 and $150 \mathrm{~ms}(1.252 \pm 0.035$ vs $1.013 \pm 0.038$ at $50 \mathrm{~ms}, 1.365 \pm 0.076$ vs $0.935 \pm 0.058$ at $100 \mathrm{~ms}, 1.018 \pm 0.017$ vs $0.96 \pm 0.03$ at $150 \mathrm{~ms}$ in the WT and KO mice, respectively). (j) Representative images of Golgi staining in the WT and KO groups ( $\mathrm{W}=5 \mathrm{mice} / \mathrm{group}$ ). ( $\mathrm{k}$ ) Quantitative data for the number of dendritic spines $(0.543 \pm 0.022 \mu \mathrm{m}$ vs $0.556 \pm 0.015 \mu \mathrm{m}$ in the WT and KO mice, $\mathrm{n}=17$ and 23 neurons/group, respectively). Scale bar $=40 \mu \mathrm{m}$. Scale bar of the enlarged image $=20 \mu \mathrm{m}$. Data are means \pm SEM and $* p<0.05$, $* * p<0.0$ I, and $* * * p<0.001$. 
functions along with upregulation of BDNF expression through antidepressant pathways and consequently alleviated depression-related behaviors. These findings could aid in the development of novel pharmaceutical antidepressant drugs.

Our findings on the behavioral association of neuronmicroglia interactions show that the STAT3 pathway in microglia may be strongly associated with antidepressive-like behavior. These behavioral experimental results could be categorized as the positive valence system according to Research Domain Criteria for emotional behavior. Despairbased behavior represented by tail suspension and forced swim tests was responsible for willingness to overcome stressful responses, by measuring motility. Similarly, behavioral processes related to hedonic responses were examined in the sucrose preference test for probing the neural systems for reward seeking behavior. Each experimental design may demonstrate partial aspects of depressive symptoms mimicking human patients' behavior; however, it is quite plausible for newly built criteria on human mental researches.

For many decades, accumulating evidence has reported a positive relationship between depression and cytokines and/ or chemokines, such as TNF- $\alpha$, IL- 1 , IL- 6 , and the CC chemokine ligand (CCL) family (Khairova et al, 2009). A recent study suggested that manipulation of the microglia activation status with microglial stimulators, such as lipopolysaccharide and M-CSF, could be a potent etiological therapeutics for depression symptomatology (Kreisel et al, 2014). For example, M-CSF could reduce the depressive-like behavior by activating microglia status under chronic stress conditions. In our microglial STAT3-deficient model, the microglial STAT3 as a sensor of the cytokine profiles was effectively depleted. Notably, the expression of M-CSF was increased in the brains of STAT3 ${ }^{\mathrm{fl} / \mathrm{fl}} ; \mathrm{LysM}_{\mathrm{Cre}} \mathrm{Cr}^{+-}$mice. The elevated mRNA levels and the secretion of M-CSF were detected in neuronal cells in in vitro co-culture system. These results implied the novel actions of M-CSF in the absence of microglial STAT3. Under altered circumstances by deletion of microglial STAT3, M-CSF can be synthesized in neuronal cells and at the same time affect the neuronal cells themselves. For example, M-CSF is produced with an autocrine/paracrine mechanism of action in distinct brain regions, including the dorsal forebrain, and cerebellum, and has an essential role in neural progenitor cell maintenance and maturation (Chitu et al, 2016). In this study, we suggest that M-CSF is involved in autocrine loops in neuronal cells.

Based on these results, we hypothesized that M-CSF actions in neuronal cells could activate certain signaling pathways for antidepressant drugs. We discovered that Akt/GSK3 $\beta$ was phosphorylated by stimulation with M-CSF in neuronal cells. Shared with the mechanisms of conventional antidepressant drugs, our findings could be helpful to take less risk for developing novel therapeutics. Thus, these results indicate that the regulation of Akt/GSK3 $\beta$ pathways by M-CSF can be a strong candidate for the development of antidepressants.

In relation to $\mathrm{BDNF}$ signaling, we first verified that $\mathrm{BDNF}$ expression, as well as the phosphorylation of ERK1/2 and Akt/GSK3 $\beta$ was increased in neuronal cells both in STAT3 ${ }^{\mathrm{fl} / \mathrm{fl}}$; LysM-Cre $^{+/-}$mice and in in vitro co-culture system in response to secreted M-CSF. M-CSF-induced ERK1/2 and Akt/GSK3 $\beta$ signaling pathways potentially work as the molecular mechanisms to regulate antidepressive-like behaviors. Many studies showed that the ERK1/2 and Akt/GSK3 $\beta$ signaling subsequently induce BDNF expression (Jope and Roh, 2006; Obata et al, 2003). BDNF production may also affect presynaptic neurotransmitter release rather than morphological changes of synapses. For this reason, it is important to note that $\mathrm{M}$-CSF regulates antidepressanttargeting mediators and BDNF expression.

In order to examine which factors from microglia could increase the release of M-CSF from neurons, we analyzed the cytokine/chemokine profiles of microglia in the STAT3deficient mouse model. The results showed that the expression of CCL2 was reduced in primary microglia isolated from STAT3 ${ }^{\mathrm{fl} / \mathrm{fl}}$;ysM-Cre $^{+/-}$mice, as well as in STAT3-silenced BV2 cells from in vitro co-culture system (Supplementary Figure S9a-c). We assumed that CCL2 in microglia contributed to the increase of M-CSF in neurons. However, the following results indicated that CCL2 had no effects on the changes of M-CSF levels in neurons (Supplementary Figure S9d). Besides, the expression level of CCL2 had no differences between the brains of WT and $\mathrm{STAT}^{\mathrm{fl} / \mathrm{fl}} ; \mathrm{LysM} \mathrm{Cre}^{+/-}$mice (Supplementary Figure S9e). These results indicate that CCL2 was not involved in the M-CSF production. Considering the modulation of M-CSF expression, alternatively, nuclear factor $-\kappa \mathrm{B}(\mathrm{NF}-\kappa \mathrm{b})$ can be an intermediate factor in neuron-microglia interactions. It was reported that NF- $\kappa \mathrm{b}$ was implicated in the transcriptional regulation of the M-CSF (Rajavashisth et al, 1995). Therefore, further studies are needed to investigate whether the STAT3-targeted factors in microglia regulate neuronal $\mathrm{M}-\mathrm{CSF}$ production via NF- $\kappa \mathrm{b}$ signaling.

When it comes to neuron-microglia cross-talk, cell-to-cell interactions have a pivotal role in intercellular communication. For example, CX3CR1/CX3CL1 signaling between microglia and neurons is involved in synaptic engulfment, resulted in synaptic elimination (Ueno et al, 2013; Zhan et al, 2014), and in the modulation of cytokine production and glutamatergic neurotransmission (Rogers et al, 2011; Scianni et al, 2013). CD200 and its receptor, CD200 receptor, also have critical roles in the interplay between neurons and microglia by controlling anti-inflammatory signaling and by maintaining them in a resting state (Hoek et al, 2000). Presumably, however, our data indicated that de novo mechanisms of neuron-microglia cross-talk would exist. Ablation of STAT3 in microglia did not alter the number of synaptic dendritic spines. The cytokine array and ELISA experiments also provided that M-CSF production occurs in neuronal cells but not IL- $1 \beta$, TNF- $\alpha$, IL-6, and IL- 10 .

As a novel antidepressant mechanism, rapid responses mainly occur through NMDA and AMPA receptor-mediated glutamatergic neurotransmission (Duman et al, 2012b). Our findings indicated that AMPA receptor-mediated synaptic activity was enhanced presynaptically without morphological changes in response to M-CSF. As previously mentioned, we determined the increase of ERK1/2 phosphorylation by stimulation of M-CSF. Regarding the ERK1/2 signaling pathways, the mEPSC frequency was decreased in the inhibition of phosphorylated ERK1/2 (Kushner et al, 2005). Thus, this implicated that M-CSF-induced ERK1/2 signaling could enhance the release probability of neurotransmitters. The findings that M-CSF enhanced glutamatergic 
neurotransmission can help elucidate novel antidepressant mechanisms for a rapid-acting antidepressant response.

In conclusion, microglial STAT3 was essential for promoting M-CSF actions on synaptic transmission, which led to antidepressive-like behavior. We propose that ERK1/2 and Akt/GSK3 $\beta$ signaling pathways are involved in BDNFdependent antidepressant behaviors via M-CSF secretion in neuronal cells. These findings may provide a novel therapeutic approach for alleviating major depressive disorders.

\section{FUNDING AND DISCLOSURE}

This study was supported by grants from the NRF funded by the Korea government (MISP; 2012R1A5A2A44671346 and MESF; 2012R1A2A2A01012897 and 2014R1A2A1A11053203 to SKY and 2012R1A5A2A44671346 to SK), the National R\&D Program for Cancer Control, Ministry of Health \& Welfare, Republic of Korea (0720540 to SKY and A120476 to SK), and Seoul National University Hospital (SNUH) Research Fund (3420130270 and 0320140100 to SKY). $\mathrm{S}-\mathrm{HK}$ received a scholarship from the BK21-plus education program provided by the National Research Foundation of Korea (NRF). The authors declare no conflict of interest.

\section{ACKNOWLEDGMENTS}

We thank Jaerong Ahn, Haeri Lee, Joohan Woo, Seung-Eon Roh, Kyung-Jin Kim, and Chung-Hyun Cho for technical support and for reading the manuscript.

\section{REFERENCES}

Audet MC, Anisman H (2013). Interplay between pro-inflammatory cytokines and growth factors in depressive illnesses. Front Cell Neurosci 7: 68.

Beurel E, Grieco SF, Jope RS (2015). Glycogen synthase kinase-3 (GSK3): regulation, actions, and diseases. Pharmacol Ther 148: 114-131.

Brites D, Fernandes A (2015). Neuroinflammation and depression: microglia activation, extracellular microvesicles and microRNA dysregulation. Front Cell Neurosci 9: 476.

Caldeira C, Oliveira AF, Cunha C, Vaz AR, Falcão AS, Fernandes A et al (2014). Microglia change from a reactive to an age-like phenotype with the time in culture. Front Cell Neurosci 8: 152.

Chabot S, Williams G, Yong VW (1997). Microglial production of TNF-alpha is induced by activated $\mathrm{T}$ lymphocytes. Involvement of VLA-4 and inhibition by interferonbeta-1b. J Clin Invest 100: 604-612.

Chen G, Huang L-D, Jiang Y-M, Manji HK (2000). The moodstabilizing agent valproate inhibits the activity of glycogen synthase kinase-3. J Neurochem 72: 1327-1330.

Chitu V, Gokhan Ş, Nandi S, Mehler MF, Stanley ER (2016). Emerging roles for CSF-1 receptor and its ligands in the nervous system. Trends Neurosci 39: 378-393.

Chuang DM, Wang Z, Chiu CT (2011). GSK-3 as a target for lithium-induced neuroprotection against excitotoxicity in neuronal cultures and animal models of ischemic stroke. Front Mol Neurosci 4: 15.

Cipriani A, Smith K, Burgess S, Carney S, Goodwin G, Geddes J (2006). Lithium versus antidepressants in the long-term treatment of unipolar affective disorder. Cochrane Database Syst Rev Cd003492.

Clausen BH, Lambertsen KL, Babcock AA, Holm TH, Dagnaes-Hansen F, Finsen B (2008). Interleukin-1beta and tumor necrosis factor-alpha are expressed by different subsets of microglia and macrophages after ischemic stroke in mice. J Neuroinflam 5: 1-18.

Couch Y, Anthony DC, Dolgov O, Revischin A, Festoff B, Santos AI et al (2013). Microglial activation, increased TNF and SERT expression in the prefrontal cortex define stress-altered behaviour in mice susceptible to anhedonia. Brain Behav Immun 29: 136-146.

Davis LL, Kabel D, Patel D, Choate AD, Foslien-Nash C, Gurguis GN et al (1996). Valproate as an antidepressant in major depressive disorder. Psychopharmacol Bull 32: 647-652.

Domino ME, Burns BJ, Silva SG, Kratochvil CJ, Vitiello B, Reinecke MA et al (2008). Cost-effectiveness of treatments for adolescent depression: results from TADS. Am J Psychiatry 165: 588-596.

Duman RS, Aghajanian GK (2012a). Synaptic dysfunction in depression: potential therapeutic targets. Science 338: 68-72.

Duman RS, Aghajanian GK, Sanacora G, Krystal JH (2016). Synaptic plasticity and depression: new insights from stress and rapid-acting antidepressants. Nat Med 22: 238-249.

Duman RS, Li N, Liu R-J, Duric V, Aghajanian G (2012b). Signaling pathways underlying the rapid antidepressant actions of ketamine. Neuropharmacology 62: 35-41.

Dwivedi Y, Rizavi HS, Conley RR, Pandey GN (2005). ERK MAP kinase signaling in post-mortem brain of suicide subjects: differential regulation of upstream Raf kinases Raf-1 and B-Raf. Mol Psychiatry 11: 86-98.

Dwivedi Y, Rizavi HS, Roberts RC, Conley RC, Tamminga CA, Pandey GN (2001). Reduced activation and expression of ERK1/2 MAP kinase in the post-mortem brain of depressed suicide subjects. J Neurochem 77: 916-928.

Einat H, Yuan P, Gould TD, Li J, Du J, Zhang L et al (2003). The role of the extracellular signal-regulated kinase signaling pathway in mood modulation. J Neurosci 23: 7311-7316.

El Kasmi KC, Holst J, Coffre M, Mielke L, de Pauw A, Lhocine N et al (2006). General nature of the STAT3-activated antiinflammatory response. J Immunol 177: 7880-7888.

Fang X, Yu SX, Lu Y, Bast RC, Woodgett JR, Mills GB (2000). Phosphorylation and inactivation of glycogen synthase kinase 3 by protein kinase A. Proc Natl Acad Sci USA 97: 11960-11965.

Felger JC, Lotrich FE (2013). Inflammatory cytokines in depression: neurobiological mechanisms and therapeutic implications. $\mathrm{Neu}$ roscience 246: 199-229.

Goodyer I, Dubicka B, Wilkinson P, Kelvin R, Roberts C, Byford S et al (2007). Selective serotonin reuptake inhibitors (SSRIs) and routine specialist care with and without cognitive behaviour therapy in adolescents with major depression: randomised controlled trial. BMJ 335: 142.

Gourley SL, Wu FJ, Kiraly DD, Ploski JE, Kedves AT, Duman RS et al (2007). Regionally specific regulation of ERK MAP kinase in a model of antidepressant-sensitive chronic depression. Biol Psychiatry 63: 353-359.

Hisaoka K, Takebayashi M, Tsuchioka M, Maeda N, Nakata Y, Yamawaki S (2007). Antidepressants increase glial cell linederived neurotrophic factor production through monoamineindependent activation of protein tyrosine kinase and extracellular signal-regulated kinase in glial cells. J Pharmacol Exp Ther 321: 148-157.

Hodes GE, Kana V, Menard C, Merad M, Russo SJ (2015). Neuroimmune mechanisms of depression. Nat Neurosci 18: 1386-1393.

Hoek RM, Ruuls SR, Murphy CA, Wright GJ, Goddard R, Zurawski SM et al (2000). Down-regulation of the macrophage lineage through interaction with OX2 (CD200). Science 290: 1768-1771.

Imai Y, Kohsaka S (2002). Intracellular signaling in M-CSF-induced microglia activation: Role of Iba1. Glia 40: 164-174.

Jope RS, Roh M-S (2006). Glycogen synthase kinase-3 (GSK3) in psychiatric diseases and therapeutic interventions. Curr Drug Targets 7: 1421-1434. 
Kamat PK, Kalani A, Tyagi N (2014). Method and validation of synaptosomal preparation for isolation of synaptic membrane proteins from rat brain. MethodsX 1: 102-107.

Karege F, Perroud N, Burkhardt S, Schwald M, Ballmann E, La Harpe $\mathrm{R}$ et al (2007). Alteration in kinase activity but not in protein levels of protein kinase $\mathrm{B}$ and glycogen synthase kinase3 beta in ventral prefrontal cortex of depressed suicide victims. Biol Psychiatry 61: 240-245.

Khairova RA, Machado-Vieira R, Du J, Manji HK (2009). A potential role for pro-inflammatory cytokines in regulating synaptic plasticity in major depressive disorder. Int J Neuropsychopharmacol 12: 561-578.

Kong E, Sucic S, Monje FJ, Reisinger SN, Savalli G, Diao W et al (2015). STAT3 controls IL6-dependent regulation of serotonin transporter function and depression-like behavior. Scientific Reports 5: 9009.

Kreisel T, Frank MG, Licht T, Reshef R, Ben-Menachem-Zidon O, Baratta MV et al (2014). Dynamic microglial alterations underlie stress-induced depressive-like behavior and suppressed neurogenesis. Mol Psychiatry 19: 699-709.

Kushner SA, Elgersma Y, Murphy GG, Jaarsma D, van Woerden GM, Hojjati MR et al (2005). Modulation of presynaptic plasticity and learning by the H-ras/extracellular signal-regulated kinase/synapsin I signaling pathway. J Neurosci 25: 9721-9734.

Mori T, Miyamoto T, Yoshida H, Asakawa M, Kawasumi M, Kobayashi T et al (2011). IL-1beta and TNFalpha-initiated IL-6STAT3 pathway is critical in mediating inflammatory cytokines and RANKL expression in inflammatory arthritis. Int Immunol 23: 701-712.

Obata K, Yamanaka H, Dai Y, Tachibana T, Fukuoka T, Tokunaga A et al (2003). Differential activation of extracellular signal-regulated protein kinase in primary afferent neurons regulates brain-derived neurotrophic factor expression after peripheral inflammation and nerve injury. J Neurosci 23: 4117-4126.

Page ME, Detke MJ, Dalvi A, Kirby LG, Lucki I (1999). Serotonergic mediation of the effects of fluoxetine, but not desipramine, in the rat forced swimming test. Psychopharmacology 147: $162-167$.

Park KH, Lee TH, Kim CW, Kim J (2013). Enhancement of CCL15 expression and monocyte adhesion to endothelial cells (ECs) after hypoxia/reoxygenation and induction of ICAM-1 expression by CCL15 via the JAK2/STAT3 pathway in ECs. J Immunol 190: 6550-6558.

Rajavashisth TB, Yamada H, Mishra NK (1995). Transcriptional activation of the macrophage-colony stimulating factor gene by minimally modified LDL. Arterioscler Thromb Vasc Biol 15: 1591.

Riazi K, Galic MA, Kuzmiski JB, Ho W, Sharkey KA, Pittman QJ (2008). Microglial activation and TNF $\alpha$ production mediate altered CNS excitability following peripheral inflammation. Proc Natl Acad Sci USA 105: 17151-17156.

Riley JK, Takeda K, Akira S, Schreiber RD (1999). Interleukin-10 receptor signaling through the JAK-STAT pathway: requirement for two distinct receptor-derived signals for anti-inflammatory action. J Biol Chem 274: 16513-16521.

Rogers JT, Morganti JM, Bachstetter AD, Hudson CE, Peters MM, Grimmig BA et al (2011). CX3CR1 deficiency leads to impairment of hippocampal cognitive function and synaptic plasticity. J Neurosci 31: 16241-16250.

Schiepers OJ, Wichers MC, Maes M (2005). Cytokines and major depression. Prog Neuropsychopharmacol Biol Psychiatry 29: 201-217.

Scianni M, Antonilli L, Chece G, Cristalli G, Di Castro MA, Limatola C et al (2013). Fractalkine (CX3CL1) enhances hippocampal N-methyl-d-aspartate receptor (NMDAR) function via d-serine and adenosine receptor type A2 (A2AR) activity. J Neuroinflam 10: 876.

Steiner J, Walter M, Gos T, Guillemin GJ, Bernstein H-G, Sarnyai Z et al (2011). Severe depression is associated with increased microglial quinolinic acid in subregions of the anterior cingulate gyrus: evidence for an immune-modulated glutamatergic neurotransmission? J Neuroinflam 8: 1-9.

Streit WJ, Mrak RE, Griffin WST (2004). Microglia and neuroinflammation: a pathological perspective. J Neuroinflam 1: 1-4.

Strekalova T, Spanagel R, Bartsch D, Henn FA, Gass P (2004). Stress-induced anhedonia in mice is associated with deficits in forced swimming and exploration. Neuropsychopharmacology 29: 2007-2017.

Tardito D, Perez J, Tiraboschi E, Musazzi L, Racagni G, Popoli M (2006). Signaling pathways regulating gene expression, neuroplasticity, and neurotrophic mechanisms in the action of antidepressants: a critical overview. Pharmacol Rev 58: 115-134.

Ueno M, Fujita Y, Tanaka T, Nakamura Y, Kikuta J, Ishii M et al (2013). Layer V cortical neurons require microglial support for survival during postnatal development. Nat Neurosci 16: 543-551.

Wake H, Moorhouse AJ, Miyamoto A, Nabekura J (2013). Microglia: actively surveying and shaping neuronal circuit structure and function. Trends Neurosci 36: 209-217.

Zhan Y, Paolicelli RC, Sforazzini F, Weinhard L, Bolasco G, Pagani F et al (2014). Deficient neuron-microglia signaling results in impaired functional brain connectivity and social behavior. Nat Neurosci 17: 400-406.

(c) (i) (3) $\odot$ This work is licensed under a Creative Commons Attribution-NonCommercial-NoDerivs $\quad 4.0$ International License. The images or other third party material in this article are included in the article's Creative Commons license, unless indicated otherwise in the credit line; if the material is not included under the Creative Commons license, users will need to obtain permission from the license holder to reproduce the material. To view a copy of this license, visit http://creativecommons.org/licenses/by-nc-nd/4.0/

(C) The Author(s) 2017

Supplementary Information accompanies the paper on the Neuropsychopharmacology website (http://www.nature.com/npp) 